\title{
Optimal Carbon Dioxide and Hydrogen Utilization in Carbon
}

\section{Monoxide Production}

\author{
Medrano-García, J.D., Ruiz-Femenia, R.* and Caballero, J.A.
}

Institute of Chemical Process Engineering, University of Alicante, PO 99E-03080

Alicante, Spain

*ruben.ruiz@ua.es

ABSTRACT: Carbon monoxide is the building block of many relevant chemical products. However, the relatively high emissions (1.396 - $2.322 \mathrm{~kg} \mathrm{CO}$-eq/kg CO) of its synthesis and separation process result in high emitting derivatives. Therefore, reducing CO synthesis emissions is the first step towards more sustainable end products. In order to tackle this problem, we propose a carbon monoxide synthesis and purification superstructure. We perform multi-objective optimizations minimizing the cost and emission of the final CO product across several case scenarios. Results show that the minimum cost solutions are achieved using partial oxidation of methane (POX) as the syngas synthesis process and cryogenic distillation as the CO separation technology. Emissions can be decreased using dry methane reforming (DMR) and pressure swing adsorption (PSA) but costs increase dramatically. Optimal $\mathrm{H}_{2}$ utilization results in a reverse water gas shift (RWGS) reactor where $\mathrm{CO}_{2}$ is consumed to produce additional CO. Off-gas valorization is key to further reducing the synthesis cost and emissions.

KEYWORDS: $\mathrm{CO}_{2}$ utilization, synthesis gas, methane reforming, carbon monoxide production, hydrogen management, superstructure decision making, multi-objective optimization

\section{ABBREVIATIONS}

ATR Auto thermal reforming 
25 CCS

26 BR

$27 \quad \mathrm{CO}_{2}$-eq

28 CR

29 DMR

30 GDP

31 GWP

$32 \quad \mathrm{HI}$

33 POX

$34 \quad$ PSA

35 RWGS

36 SMR

37 STAC

$38 \quad \mathrm{TR}$

$39 \quad$ WGS
Carbon Capture and Storage

Bi-reforming

Carbon dioxide equivalent

Combined reforming

Dry methane reforming

Generalized Disjunctive Programming

Global Warming Potential

Heat integration

Partial oxidation

Pressure swing adsorption

Reverse water gas shift

Steam methane reforming

Specific total annualized cost

Tri-reforming

Water gas shift

\section{NOMENCLATURE}

\section{Indices}

$42 \quad b \quad$ bypass: $B=\{$ bypass 1 , bypass2, bypass 3

$43 \quad$ c cold stream: $C=\left\{(c)_{c=1}^{c=19}\right\}$ 
Set relation between RWGS reactor $r w g s$ and cold stream $c$ : $C R W G S_{r w g s, c}=\left\{\begin{array}{l}(1, c 12),(1, c 13),(2, c 14),(2, c 15), \\ (3, c 16),(3, c 17),(4, c 18),(4, c 19)\end{array}\right\}$

Set relation between syngas technology syn and cold stream $c$ : $\operatorname{CSYN}_{s y n, c}=\left\{\begin{array}{l}(S M R, c 1),(S M R, c 2),(P O X, c 3),(A T R, c 4),(C R, c 5),(C R, c 6), \\ (D M R, c 7),(D M R, c 8),(B R, c 9),(B R, c 10),(T R, c 11)\end{array}\right\}$ side draw: $D=\left\{\right.$ water, $\mathrm{CO}_{2}, \mathrm{H}_{2}$ pure, $\mathrm{H}_{2}$-rich, $\left.\mathrm{CO}\right\}$ side draw end use: $E=$ \{syngas synthesis, recycle, RWGS reactor, fuel cell, fuel gas, byproduct, storage, waste $\}$

hot stream: $H=\left\{(h)_{h=1}^{h=13}\right\}$

Set relation between RWGS reactor $r w g s$ and hot stream $h$ : HRWGS $_{\text {rwgs }, h}=\{(1, h 10),(2, h 11),(3, h 12),(4, h 13)\}$

Set relation between RWGS reactor $r w g s$ and hot stream $h$ : $H_{S Y N} N_{s y n, h}=\left\{\begin{array}{l}(S M R, h 1),(P O X, h 2),(A T R, h 3),(C R, h 4), \\ (C R, h 5),(D M R, h 6),(B R, h 7),(T R, h 8),(T R, h 9)\end{array}\right\}$

process units: $I=$ \{syngas synthesis, flash separator, $\mathrm{CO}_{2}$ absorber1, PSA $\mathrm{H}_{2}$, cryogenic distillation, PSA CO, $\mathrm{CO}$ absorber, $\mathrm{CO}_{2}$ absorber2, fuel cell, RWGS reactor\}

components: $J=$ \{methane, steam/water, $\mathrm{O}_{2}, \mathrm{CO}_{2}, \mathrm{CO}, \mathrm{H}_{2}$ \}

component: $J^{\prime}=\left\{j^{\prime} \in J: j^{\prime}\right.$ is the reference component of process unit i\} : $\forall i \in I$

unit types: $K=\{$ reformer reactor, compressor, exchanger/heater/cooler, vessel, fuel cell $\}$

off-gas $\mathrm{H}_{2} / \mathrm{CO}$ ratio: $O G=\{0,1,1.5,2,2.5,100\}$

reverse water gas shift reactor: $R W G S_{i}=\{1,2,3,4\}: i=\{$ RWGS reactor $\}$

process sections: $S=$ \{syngas synthesis, separation, RWGS reactor $\}$

heat integration stage: $S T=\left\{(s t)_{s t=1}^{s t=58}\right\}$

syngas technologies: $\operatorname{SYN}_{i}=\{\mathrm{SMR}, \mathrm{POX}, \mathrm{ATR}, \mathrm{CR}, \mathrm{DMR}, \mathrm{BR}, \mathrm{TR}\}: i=$ \{syngas synthesis\}

utilities: $U=\{$ natural gas, cooling water, power $\}$

\section{Parameters}




\begin{tabular}{|c|c|c|}
\hline 73 & $A F$ & Annualization factor \\
\hline 74 & $b_{i}$ & Additional utilities required by process unit $i$ [various units] \\
\hline 75 & $B_{k}^{1}$ & Bare module parameter 1 of unit type $k$ \\
\hline 76 & $B_{k}^{2}$ & Bare module parameter 2 of unit type $k$ \\
\hline 77 & $c_{i k}^{f}$ & Fixed cost parameter of unit type $k$ in process unit $i[\$]$ \\
\hline 78 & $c_{i k}^{v}$ & Variable cost parameter of unit type $k$ in process unit $i$ [\$/capacity units] \\
\hline 79 & $F_{\max }$ & Maximum allowed molar flow [kmol/h] \\
\hline 80 & $F_{k}^{M}$ & Material factor of unit type $k$ \\
\hline 81 & $F_{k}^{P}$ & Pressure factor of unit type $k$ \\
\hline $\begin{array}{l}82 \\
83\end{array}$ & $G_{j}$ & $\begin{array}{l}\text { Mole of } \mathrm{CO}_{2} \text { produced by the complete combustion per mole of } \\
\text { component } j \text { with air }\left[\mathrm{kmol} \mathrm{CO}_{2} / \mathrm{kmol} j\right]\end{array}$ \\
\hline 84 & $M_{\mathrm{CO}_{2}}$ & Molar mass of $\mathrm{CO}_{2}\left[\mathrm{~kg} \mathrm{CO}_{2} / \mathrm{kmol} \mathrm{CO}_{2}\right]$ \\
\hline 85 & & \\
\hline 86 & $\sigma_{j}$ & Cost of component $j[\$ / \mathrm{kmol} j]$ \\
\hline 87 & $\Delta H_{j}^{c}$ & Enthalpy of combustion of component $j[\mathrm{~kJ} / \mathrm{kmol} j]$ \\
\hline 88 & $\Delta T_{s t}$ & Temperature difference between stage $s t$ and $s t+1$ \\
\hline 89 & $\phi_{i j d}$ & Fraction separated of component $j$ in process unit $i$ and side draw $d$ \\
\hline 90 & $\varphi_{u}$ & Cost contribution of utility $u[\$ / \mathrm{kW}]$ \\
\hline 91 & $\lambda_{j}$ & Emission of component $j[\mathrm{~kg} \mathrm{CO}$-eq/kmol $j]$ \\
\hline 92 & $\eta_{c}$ & Fuel gas combustion efficiency \\
\hline 93 & $\theta_{u}$ & Emission contribution of utility $u[\mathrm{~kg} \mathrm{CO} 2-\mathrm{eq} / \mathrm{kW}]$ \\
\hline 94 & $\psi_{i}$ & Emission contribution of additional utilities [ $\mathrm{kg} \mathrm{CO}_{2}$-eq/various units] \\
\hline 95 & $\omega_{i}$ & Cost contribution of additional utilities [\$/various units] \\
\hline 96 & Variables & \\
\hline 97 & $\mathrm{cap}_{i}$ & Capital cost of process unit $i[\$]$ \\
\hline 98 & cost $_{\text {og }}$ & Off-gas valorization associated revenue $[\$ / \mathrm{kg}]$ \\
\hline 99 & emission $_{i}$ & Emission of process unit $i[\mathrm{~kg} \mathrm{CO} 2-\mathrm{eq} / \mathrm{h}]$ \\
\hline
\end{tabular}


emission $_{\text {og }}$ Off-gas valorization associated abated emission [kg CO 2 -eq $\left./ \mathrm{kg}\right]$

101

102

103

104

$105 \quad F_{j}^{f g}$

106

107

108

109

110

111

112

113

114

115

116

117

118

119

120

121

122

123

124

$F_{i j d e}$ emission $^{f g} \quad$ Emission related to fuel gas combustion $[\mathrm{kg} \mathrm{CO} 2-\mathrm{eq} / \mathrm{h}]$

Molar flow of component $j$ in side draw $d$ end use $e$ from process unit $i[\mathrm{kmol} / \mathrm{h}]$

Additional $\mathrm{CO}_{2}$ molar flow that enters the system [kmol/h]

Fuel gas molar flow of component $j[\mathrm{kmol} / \mathrm{h}]$

Inlet bypass $b$ molar flow of component $j[\mathrm{kmol} / \mathrm{h}]$

Outlet bypass $b$ molar flow of component $j[\mathrm{kmol} / \mathrm{h}]$

Inlet process unit $i$ molar flow of component $j[\mathrm{kmol} / \mathrm{h}]$

Outlet process unit $i$ molar flow of component $j[\mathrm{kmol} / \mathrm{h}]$

Product molar flow of component $j[\mathrm{kmol} / \mathrm{h}]$

Product of the molar flow and heat capacity of cold stream $c$ in stage $s t$ per $\mathrm{kmol} / \mathrm{h}$ of component $j^{\prime}\left[\mathrm{kW} \cdot{ }^{\circ} \mathrm{C} \cdot \mathrm{h} / \mathrm{kmol} j^{\prime}\right]$

Product of the molar flow and heat capacity of hot stream $h$ in stage $s t$ per $\mathrm{kmol} / \mathrm{h}$ of component $j^{\prime}\left[\mathrm{kW} \cdot{ }^{\circ} \mathrm{C} \cdot \mathrm{h} / \mathrm{kmol} j^{\prime}\right]$

$\mathrm{H}_{2} / \mathrm{CO} \quad$ Off-gas $\mathrm{H}_{2} / \mathrm{CO}$ molar ratio

$o p_{i} \quad$ Operating cost of process unit $i[\$ / \mathrm{h}]$

Total cold services required by the system [kW]

Hot services required by process unit $i[\mathrm{~kW}]$

Hot services provided to process unit $i$ by fuel gas combustion [kW]

Total hot services required by the system $[\mathrm{kW}]$

Total externally supplied hot services required by the system [kW]

Residual heat that leaves stage st $[\mathrm{kW}]$

Raw material molar flow of component $j[\mathrm{kmol} / \mathrm{h}]$

Binary variables associated to the existence of process unit $i$ 
128 Carbon monoxide is a precursor of many important chemical products (Figure 1). It is most commonly obtained through synthesis gas (syngas) separation, which is mainly an $\mathrm{H}_{2} / \mathrm{CO}$ mixture, although it can also contain unreacted methane and unseparated carbon dioxide [1]. Hence, this process produces an excess gas byproduct which is usually hydrogen-rich. This off-gas is often used as fuel within the syngas generation and separation section or in downstream applications, although it can also serve as a raw material of other products since it contains valuable hydrogen.

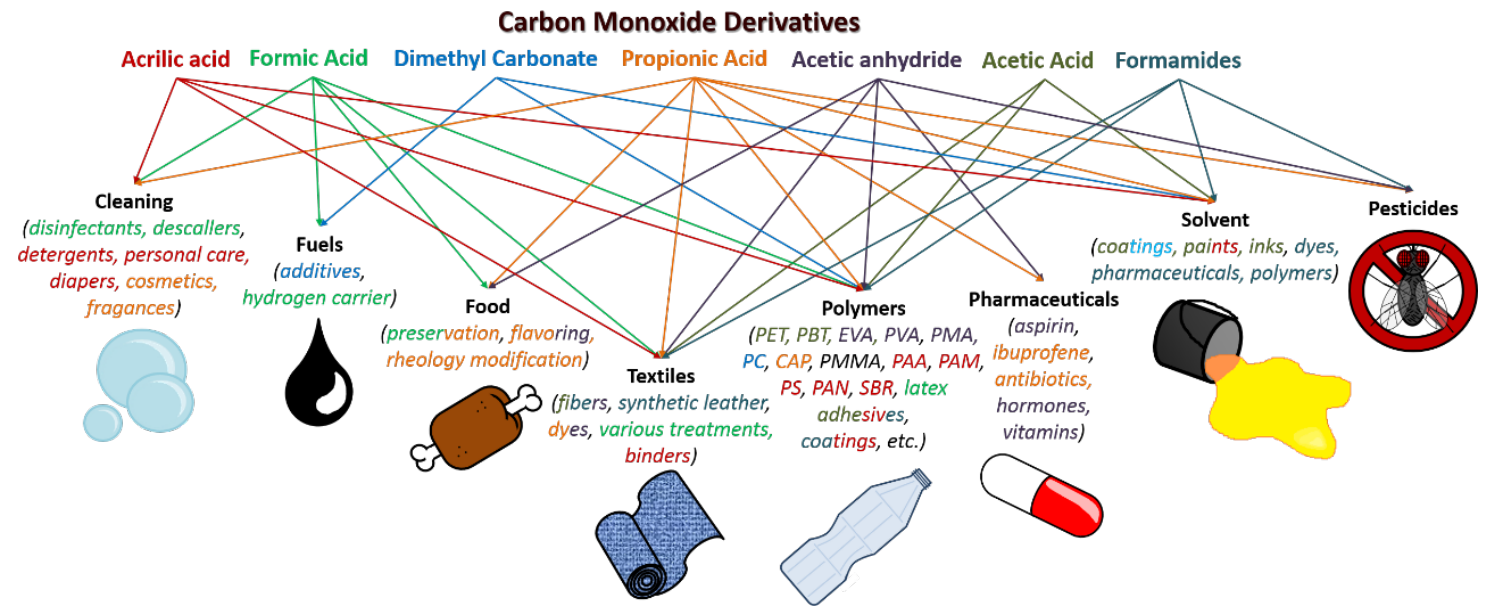

137 The synthesis and separation of carbon monoxide has a more than appreciable carbon 138 footprint. The whole process emits approximately from 1.396 to $2.322 \mathrm{~kg}$ of carbon dioxide equivalent (kg CO 2 -eq) per $\mathrm{kg}$ of $\mathrm{CO}$ [10]. Therefore, due to the importance of the gas, achieving a reduction of these manufacture emissions may contribute to mitigate the environmental burden.

142 In a previous work [11], we studied syngas generation and ratio adjustment for several compositions and product pressures. The most remarkable result, at least from an environmental point of view, was that with an $\mathrm{H}_{2} / \mathrm{CO}$ ratio of one and low product 
pressures, the production of this syngas can consume more $\mathrm{CO}_{2}$ than it emits both directly and indirectly, down to a minimum value of about $-0.2 \mathrm{~kg} \mathrm{CO} 2-\mathrm{eq} / \mathrm{kg}$ syngas. This result

147 is directly tied to the need of hydrogen: the less hydrogen required, the less costly and less emitting the synthesis is. According to these results, a further reduction of the $\mathrm{H}_{2} / \mathrm{CO}$ ratio could lead to an even higher $\mathrm{CO}_{2}$ utilization process. Hence, completely removing $\mathrm{H}_{2}$ from syngas in order to produce pure $\mathrm{CO}$ may result in an interesting case of study. We propose a process superstructure in which several syngas synthesis processes, $\mathrm{H}_{2}$, $\mathrm{CO}$ and $\mathrm{CO}_{2}$ separation units and different off-gas utilization alternatives (fuel gas, fuel cell, Reverse Water Gas Shift reaction) are included. The aim of this superstructure is to find the optimal configuration that minimizes the cost $(\$ / \mathrm{kg} \mathrm{CO})$ and/or the emission $\left(\mathrm{kg} \mathrm{CO}_{2}\right.$ eq/kg $\mathrm{CO}$ ) by using classic, $\mathrm{CO}_{2}$-consuming and more environmentally friendly technologies.

The superstructure is modelled using the Generalized Disjunctive Programming (GDP) and the resulting disjunctions are transformed into algebraic equations through the Hull Reformulation [12]. We tackle this optimization problem solving the resulting MixedInteger Non-Linear Program (MINLP) model as a multi-objective optimization problem using the epsilon constraint method [13], minimizing the environmental (GWP) and economic (Specific Total Annualized Cost, STAC) indicators. Results show that the byproduct management is the key to achieve a great reduction both in cost and emissions of the synthesis process.

\section{Methods and models}

The proposed process superstructure is shown in Figure 2. Methane and the selected reformer agents enter one of the possible syngas synthesis processes. Then, water is removed via condensation, followed by the possibility of removing $\mathrm{CO}_{2}$ in an amine 

from the resulting stream, or it can simply advance to the CO separation section, where cryogenic distillation, absorption, or PSA can be used for the task. Finally, the product $\mathrm{CO}$ stream can be subjected to a further $\mathrm{CO}_{2}$ removal if needed. Hydrogen rich and offgas streams resulting from the separation technologies are given the possibility of being recycled, used as fuel (combustion or in a fuel cell) or become a byproduct stream for utilization in a subsequent synthesis. A more in depth analysis of Figure 2 is given in the following subsections.

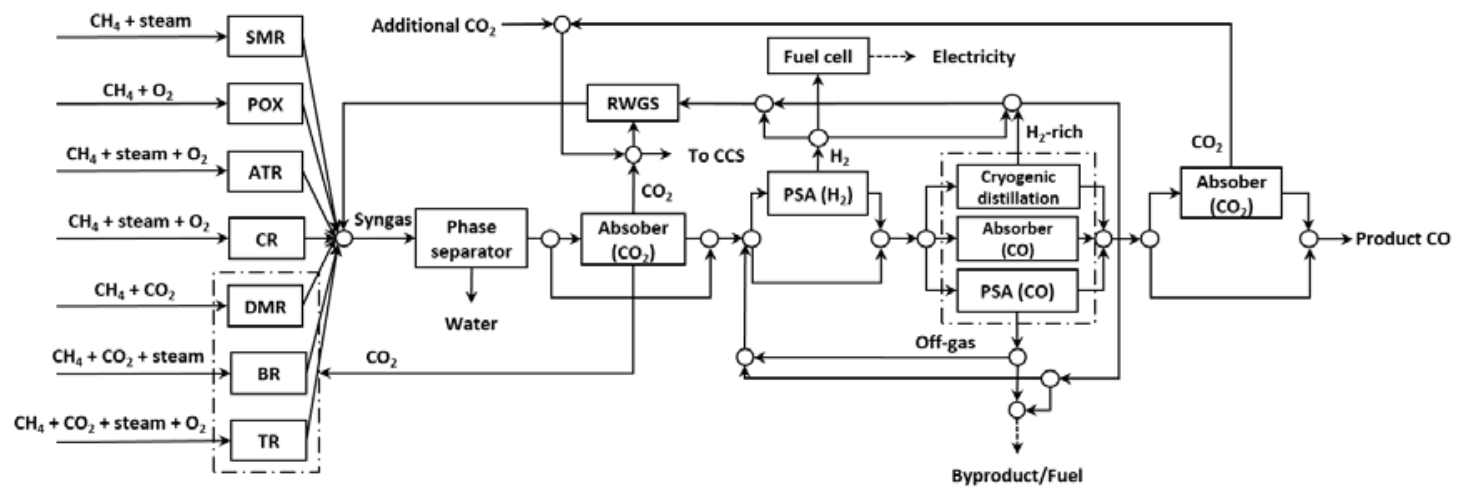

Figure 2. Proposed carbon monoxide synthesis and separation superstructure

\subsection{Synthesis gas production}

Carbon monoxide can be produced by methane reforming syngas synthesis and its subsequent separation $[1,14]$. The synthesis can be carried out by several technologies. Steam methane reforming (SMR) uses steam as reforming agent in an endothermic reaction that produces high hydrogen content syngas $[15,16]$. This is the most used worldwide tehnology, especially when hydrogen is desired as the main or secondary product [17]. Non-catalitic partial oxidation (POX) uses oxygen as reforming agent in a high enxothermic reaction that can reach over $1200{ }^{\circ} \mathrm{C}$ [18], and its catalytic version, auto-thermal reforming (ATR), uses a mixture of oxygen and steam in an also overall 
exothermic process $[17,19]$. These two technologies are the most used after SMR, especially when syngas with low to medium hydrogen content is the main sought product $[20,21]$. The fourth techonology is combined reforming (CR), which consists in an SMR followed by an ATR reformer reactor [22]. The so called dry methane reforming (DMR) uses $\mathrm{CO}_{2}$ as the sole reforming agent in order to produce a low hydrogen content syngas in a highly endothermic energy intensive reaction [20,21,23]. The particularity of this process resides in its capability of net consuming $\mathrm{CO}_{2}$ in the production of low pressure and $\mathrm{H}_{2} / \mathrm{CO}$ ratios syngas [11]. Bi-reforming consists in the addition of $\mathrm{CO}_{2}$ to the $\mathrm{SMR}$ reaction [22]. This change reduces the hydrogen content in the product but allows for an easier syngas composition adjustment, in addition to consuming $\mathrm{CO}_{2}$ in the process [17]. Finally, tri-reforming uses all three reforming agents (steam, oxygen and $\mathrm{CO}_{2}$ ) so as to produce syngas with an $\mathrm{H}_{2} / \mathrm{CO}$ ratio below two [24,25]. The selected process for $\mathrm{CO}$ production is largely dependent on a company's own technologies and licenses [26], although POX, ATR and SMR are usually the preferred choices [20,27].

These processes were simulated in Aspen HYSYS v9.0 using the most common feed ratios and operating pressures and temperatures found in the bibliography. From the simulations, we propose linear models addressing raw material and utility requirements, conversion and capital costs. These models as well as a more detailed information on the simulations and operating parameters can be found in [11].

\subsection{Carbon monoxide separation}

Separation of carbon monoxide is mainly carried out using three different technologies [14,28]: cryogenic distillation, chemical absorption (COSORB) and pressure swing adsorption (PSA). Cryogenic distillation is the most widley used [29], while absorption and PSA are more suitable when $\mathrm{N}_{2}$ is present in the mixture [30]. Carbon monoxide 
212 purities and recoveries, as well as the cost and emission per mass unit of CO separated 213 are shown in Table 1.

Table 1. Main carbon monoxide separation technologies and characteristics [28].

\section{Cryogenic distillation COSORB PSA}

\section{CO Purity [\%]}

CO Recovery [\%]

Cost $[\$ /$ ton CO]

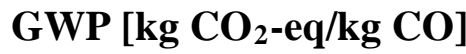

$97-99[30,31]$

90

$71[29]$

$0.587[33]$
99

99

90

$200[32] \quad 140[32]$

$0.190[32] 0.094[32]^{*}$
215

216

217

218

219

220

221

222

223

* 1.4 bar inlet pressure

2.3. Hydrogen optimal usage

2.3.1. Fuel gas production for energy generation

The continuous availability of hydrogen combined with its clean combustion makes it an excellent candidate to be used as fuel in the syngas synthesis process and the following downstream applications. Recycling the fuel gas reduces natural gas demand, and thus the cost and — most importantly — the emission of heating. The energy produced by the fuel gas is calculated as:

$$
\sum_{i} Q_{i}^{f g}=\sum_{j} \Delta H_{j}^{c} F_{j}^{f g} \eta_{c}
$$

224 Where $Q_{i}^{f g}(\mathrm{~kW})$ is the energy produced by combustion of the fuel gas which is sent to process unit $i, \Delta H_{j}^{c}$ is the enthalpy of combustion of component $j$ (Table 2), $F_{j}^{f g}$ is the fuel gas molar flow of component $j(\mathrm{kmol} / \mathrm{s})$ and $\eta_{c}$ is the efficiency of the combustion, 
242 where $G_{j}$ is the molar production of $\mathrm{CO}_{2}$ after combustion with air of component $j$ (Table

assumed at 0.8. The total hot services energy demand of the system that has to be externally supplied, $q_{\text {hot }}$, is calculated using Eq.(2) and Eq.(3), subjected to Eq.(4):

$$
Q_{\text {hot }}=\sum_{i} Q_{i}
$$

$$
q_{h o t}=\sum_{i}\left(Q_{i}-Q_{i}^{f g}\right) \quad \forall i \in I
$$

$$
Q_{i}-Q_{i}^{f g} \geq 0 \quad \forall i \in I
$$

where $Q_{i}$ is the hot services energy demand of process unit $i$ and $Q_{h o t}$ is the total energy demand (hot services) of the system, both in $\mathrm{kW}$. If part of the energy is unused by the system, it is sold assuming the same price if it was produced by burning natural gas (9.237 \$/MWh [34]). On the other hand, its $\mathrm{CO}_{2}$ emissions are calculated assuming total combustion of the gas minus the avoided emissions of the same quantity of natural gas based energy would produce (212.2 kg CO2-eq/MWh [10]).

Unreacted methane and unseparated carbon monoxide and dioxide can be part of the fuel gas, which makes its combustion not completely emission free. Total combustion of the fuel gas is assumed when computing the emission:

$$
\text { emission }^{f g}=\sum_{j} F_{j}^{f g} G_{j} M_{\mathrm{CO}_{2}}
$$

2), $M_{\mathrm{CO}_{2}}$ is the molar mass of $\mathrm{CO}_{2}(44 \mathrm{~kg} / \mathrm{kmol})$ and emission ${ }^{f g}$ is the mass flow of $\mathrm{CO}_{2}$ produced by combustion of the fuel gas $(\mathrm{kg} / \mathrm{s})$. 
247 fuel gas components in this system.

\begin{tabular}{|c|c|c|c|c|}
\hline & $\mathbf{H}_{2}$ & $\mathrm{CH}_{4}$ & $\mathrm{CO}$ & $\mathrm{CO}_{2}$ \\
\hline$\Delta H^{c}{ }_{j}[\mathrm{~kJ} / \mathbf{k m o l}]$ & 241814 & 802518 & 283200 & - \\
\hline Cost [\$/MWh] & - & $9.237[34]$ & - & - \\
\hline$G_{j}\left[\mathrm{kmol} \mathrm{CO}{ }_{2} / \mathrm{kmol}_{j}\right]$ & - & 1 & 1 & 1 \\
\hline
\end{tabular}

248

\subsubsection{Off-gas production}

250

The production of an off-gas byproduct is an alternative to the fuel gas route. This approach is interesting when downstream applications require hydrogen or syngas (obtained by leaving unseparated CO) in subsequent synthesis. Example of this are formic acid [5], acetic acid [7] or dimethyl carbonate synthesis [4]. Since this gas is a byproduct, the emission of its components is not included in the environmental indicator save for the carbon dioxide. $\mathrm{A} \mathrm{CO}_{2}$ absorber is assumed to remove $96 \%$ of the gas from the stream with a cost of $43.06 \$$ ton of $\mathrm{CO}_{2}$ [35]. The absorber is needed to avoid a $\mathrm{CO}_{2}$ "leak" through the off-gas, since omitting its contribution would derive in the system removing the maximum quantity possible through the byproduct. Regardless, the option of using part of this off-gas to fuel sections of the superstructure remains available. The economic $\left(\right.$ cost $_{o g}, \$ / \mathrm{kg}$ ) and environmental (emission ${ }_{\text {og }}, \mathrm{kg} \mathrm{CO}$-eq $/ \mathrm{kg}$ ) profit associated to the offgas utilization is computed using the following correlations, which are adjusted using bibliographic and experimental data (Appendix A, Table A. 7):

263

$$
\text { cost }_{\text {og }}=\left\{\begin{array}{l}
1.58-1.436\left(\mathrm{H}_{2} / \mathrm{CO}\right) \quad \forall\left(\mathrm{H}_{2} / \mathrm{CO}\right) \in[0,1] \\
0.0721+0.1673\left(\mathrm{H}_{2} / \mathrm{CO}\right)-0.1222\left(\mathrm{H}_{2} / \mathrm{CO}\right)^{2}+0.02733\left(\mathrm{H}_{2} / \mathrm{CO}\right)^{3} \quad \forall\left(\mathrm{H}_{2} / \mathrm{CO}\right) \in(1,2.5) \\
0.117+0.01463\left(\mathrm{H}_{2} / \mathrm{CO}\right) \quad \forall\left(\mathrm{H}_{2} / \mathrm{CO}\right) \in[2.5,10] \\
1.58 \quad \forall\left(\mathrm{H}_{2} / \mathrm{CO}\right) \in(10, \infty)
\end{array}\right.
$$


emission $_{\text {og }}=\left\{\begin{array}{l}1.859-1.261\left(\mathrm{H}_{2} / \mathrm{CO}\right) \quad \forall\left(\mathrm{H}_{2} / \mathrm{CO}\right) \in[0,1] \\ 0.3376\left(\mathrm{H}_{2} / \mathrm{CO}\right)^{3}-1.469\left(\mathrm{H}_{2} / \mathrm{CO}\right)^{2}+2.035\left(\mathrm{H}_{2} / \mathrm{CO}\right)-0.3043 \quad \forall\left(H_{2} / \mathrm{CO}\right) \in(1,2.5) \\ 0.8399+0.01353\left(\mathrm{H}_{2} / \mathrm{CO}\right) \quad \forall\left(H_{2} / \mathrm{CO}\right) \in[2.5,10] \\ 2.1924 \quad \forall\left(\mathrm{H}_{2} / \mathrm{CO}\right) \in(10, \infty)\end{array}\right.$

where $\mathrm{H}_{2} / \mathrm{CO}$ is the off-gas molar hydrogen to carbon monoxide ratio.

\subsubsection{Reverse water gas shift reaction}

269

270

271

272

274

275

276

277

278

279

Table 3. RWGS reaction $\mathrm{CO}_{2}$ conversion [38]. less providing results in $100 \%$ CO selectivity (Table 3).

\begin{tabular}{ccccc}
\hline $\mathbf{C O}_{2}$ conversion [\%] & 11.6 & 45.0 & 77.6 & 85.9 \\
$\mathbf{T}\left[{ }^{\circ} \mathbf{C}\right]$ & 300 & 350 & 400 & 450 \\
P [bar] & & \multicolumn{2}{c}{1} & \\
$\mathbf{H}_{2} / \mathbf{C O}[\mathrm{mol} / \mathrm{mol}]$ & & \multicolumn{3}{c}{7}
\end{tabular}

$$
\mathrm{CO}+\mathrm{H}_{2} \mathrm{O} \underset{\text { RWGS }}{\stackrel{\text { WGS }}{\rightleftarrows}} \mathrm{H}_{2}+\mathrm{CO}_{2}
$$

Under $600{ }^{\circ} \mathrm{C}$, the methanation reaction takes place simultaneously, and while under 800 ${ }^{\circ} \mathrm{C}$, carbon deposition occurs [37]. However, it has been reported [38] that using a specific $\mathrm{NiO} /$ silica based catalyst negates these adverse effects, with low $\mathrm{NiO}$ charges of $15 \%$ or 
We perform simulations in Aspen HYSYS v9.0 using the temperatures, pressure, feed ratio and conversions stated in Table 3. The results of the simulations (energy requirements) allow us to build linear equations to model the reactor. The related data is contained in the Appendix tables (Table A.4, Table A.5 and Table B.1).

\subsubsection{Electricity generation}

Renewable electricity by hydrogen reverse electrolysis in a fuel cell is no doubt an efficient and clean energy source. The main inconvenience it presents is hydrogen availability (generation and transport), which usually increases its cost compared to classic fossil fuel electricity [39]. In this particular scenario, since hydrogen is a byproduct of the main synthesis, it could be considered using part of it to produce clean electricity, cutting the need of a renewable hydrogen source. Commercial proton exchange membrane (PEM) fuel cells can produce $1 \mathrm{MW}$ per $750 \mathrm{Nm}^{3} / \mathrm{h} \mathrm{H}_{2}$ over $99.99 \%$ purity [40]. A PSA unit is installed in order to achieve this purity [41]. Typical PSA unit recovery for hydrogen production is in the range of $70-95 \%$ at high purity (>99.999 \%) $[42,43]$.

\subsection{Mathematical modelling of the superstructure}

\subsubsection{Carbon monoxide product line}

As seen in Figure 2, raw materials enter the chosen syngas synthesis process at the required ratio. Only one process is allowed to be selected per optimization. More details on the modelling of this section can be found in [11]. Then, the syngas product is sent to the separation section. First, a phase separator working at $40{ }^{\circ} \mathrm{C}$ is considered to remove all water contained in the syngas. Next, the option of removing $\mathrm{CO}_{2}$ (96 \% recovery, 43.06 \$/ton [35]) is given. We formulate these options using disjunctions, whose general formulation is as follows: 


$$
\left[\begin{array}{c}
Y_{i} \\
\operatorname{cap}_{i}=\sum_{k}\left(c_{i k}^{f}+c_{i k}^{v} F_{i j^{\prime}}^{i n}\right)\left(B_{k}^{1}+B_{k}^{2} F_{k}^{M} F_{k}^{P}\right) \\
0 \leq \sum_{j} F_{i j}^{i n} \leq F_{\max } \\
0 \leq \sum_{j} F_{i j}^{\text {out }} \leq F_{\max } \\
0 \leq \sum_{e} \sum_{d} \sum_{j} F_{i j d e} \leq F_{\max }
\end{array}\right] \vee\left[\begin{array}{c}
\neg Y_{i} \\
F_{i j}^{i n}=0 \\
F_{i j}^{\text {out }}=0 \\
F_{i j d e}=0 \\
\operatorname{cap}_{i}=0
\end{array}\right] \forall i, j, j^{\prime} \in I \times J
$$

where $Y_{i}$ is the Boolean variable related to the existence of the unit. If this variable value is "true", the unit exists and the process flows and cost associated to it also do, otherwise, these variables are zero. This disjunction can be reformulated into a set of algebraic equations using a binary variable $\left(y_{i}\right)$ which adopts the values 1 or 0 if the corresponding Boolean variable is true or false, respectively. Since all the equations enclosed in the disjunction are linear, we apply the Hull reformulation [12]. This reformulation is as follows:

$$
\begin{gathered}
\operatorname{cap}_{i}=\sum_{k}\left[\left(c_{i k}^{f} y_{i}+c_{i k}^{v} F_{i j^{\prime}}^{i n}\right)\left(B_{k}^{1}+B_{k}^{2} F_{k}^{M} F_{k}^{P}\right)\right] \quad \forall i, j^{\prime} \in I \times J \\
0 \leq \sum_{j} F_{i j}^{i n} \leq F_{\max } y_{i} \quad \forall i \in I \\
0 \leq \sum_{j} F_{i j}^{\text {out }} \leq F_{\text {max }} y_{i} \quad \forall i \in I \\
0 \leq \sum_{e} \sum_{d} \sum_{j} F_{i j d e} \leq F_{\max } y_{i} \quad \forall i \in I
\end{gathered}
$$

The capital cost of unit $i$ is referred as $\operatorname{cap}_{i}(\$ / \mathrm{h})$, while $c_{i k}^{f}$ and $c_{i k}^{v}$ are the fixed and variable cost parameters of unit $i$ and equipment type $k$ estimated from linearizations of the models proposed by Turton et. al [44] (Table A.2). $F_{k}^{M}$ and $F_{i k}^{P}$ are the material and pressure factors associated to equipment type $k$ while $B_{k}^{1}$ and $B_{k}^{2}$ are the bare module parameters of said process unit types. $F_{i j^{\prime}}^{\text {in }}(\mathrm{kmol} / \mathrm{h})$ is the inlet molar flow of a specific 
component $j$ ' used for calculating variable costs and emissions, which is different in each unit $i$ and is usually tied to the main separation component of said unit (Table 4). $F_{i j}^{i n}$ and $F_{i j}^{\text {out }}$ are the inlet and outlet molar flows of component $j$ in unit $i(\mathrm{kmol} / \mathrm{h}), F_{i j d e}$ are component $j$, unit $i$, side draw $d$ molar flows sent to end use $e$ in $(\mathrm{kmol} / \mathrm{h})$ and $F_{\max }$ is the allowed upper limit of the molar flow (10 kmol/s). In addition to Eqs.(10)-(13), the other common equations needed for modelling the process units are:

$$
\begin{gathered}
F_{i j}^{o u t}=F_{i j}^{i n}-\sum_{e} \sum_{d} F_{i j d e} \quad \forall i, j \in I \times J \\
\sum_{e} F_{i j d e}=\phi_{i j d} F_{i j}^{i n} \quad \forall i, j, d \in I \times J \times D \\
\text { emission }_{i}=\left(\sum_{u} a_{i u} \theta_{u}+b_{i} \psi_{i}\right) F_{i j^{\prime}}^{i n}-Q_{i}^{f g} \theta_{\text {natural gas }} \quad \forall i, j^{\prime} \in I \times J \\
\text { op }_{i}=\left(\sum_{u} a_{i u} \varphi_{u}+b_{i} \omega_{i}\right) F_{i j^{\prime}}^{i n}-Q_{i}^{f g} \varphi_{\text {natural gas }} \quad \forall i, j^{\prime} \in I \times J
\end{gathered}
$$

where $\phi_{i j d}$ is a parameter that fixes the recovery of component $j$ in unit $i$ and side draw $d$. The parameter $a_{i u}\left(\mathrm{~kW} / \mathrm{kmol} j^{\prime}\right)$ states how much utility $u$ (natural gas, cooling water, electricity) is needed by unit $i, \theta_{u}$ is the equivalent $\mathrm{CO}_{2}$ emission of utility $u(\mathrm{~kg}$ $\left.\mathrm{CO}_{2}-\mathrm{eq} / \mathrm{kW}\right), b_{i}$ is a binary parameter that adds additional contributions, like the use of a solvent, to unit $i$, and $\psi_{i}\left(\mathrm{kgCO}_{2}\right.$-eq $\left./ \mathrm{kmol}^{\prime}\right)$, is the input of said contributions to the process emission ( emission $_{i}$, in $\mathrm{kgCO}_{2}$-eq/h). The operating cost ( $\left.o p_{i}\right)$ makes use of the same $a_{i u}$ and $b_{i}$ parameters plus their conversion to costs $\varphi_{u}(\$ / \mathrm{kW})$ and $\omega_{i}\left(\$ / \mathrm{kmol} j^{\prime}\right)$. These parameters can be found in Appendix A (Table A.3, Table A.4 and Table A.5). 
Table 4. Main components and side draws of process unit $i$.

\begin{tabular}{lcc}
\hline \multicolumn{1}{c}{ Unit $\boldsymbol{i}$} & Component $\boldsymbol{j}$ ' & Side draw $\boldsymbol{d}$ \\
\hline Reformer reactor & Methane & - \\
Flash separator & Water & Water \\
$\mathrm{CO}_{2}$ absorbers & $\mathrm{CO}_{2}$ & $\mathrm{CO}_{2}$ \\
$\mathrm{H} 2$ PSA & $\mathrm{H}_{2}$ & $\mathrm{H}_{2}$ pure \\
Cryogenic distillation & $\mathrm{CO}$ & $\mathrm{H}_{2}$-rich, CO \\
CO PSA & $\mathrm{CO}$ & CO \\
CO absorber & $\mathrm{CO}_{2}$-rich, CO \\
Fuel cell & $\mathrm{H}_{2}$ & - \\
RWGS reactor & $\mathrm{CO}_{2}$ & - \\
\hline
\end{tabular}

345 After the $\mathrm{CO}_{2}$ absorber, the gas flow encounters a PSA unit that prioritizes $\mathrm{H}_{2}$ separation.

346 Here, the same situation, where the unit may or may not exist, is found. The modelling of 347 this unit is equivalent to the absorber, using Eq.(10)-(17) along with the appropriate 348 parameters (Table A.2 - Table A.5). In addition, for both, this and the absorber case, the use of a bypass is proposed as an alternative option if the process unit is not selected, although it can still be chosen in case only a fraction of the gas of interest has to be removed:

$$
\begin{gathered}
F_{b j}^{\text {in }}=F_{b j}^{\text {out }} \quad \forall b, j \in B \times J \\
F_{r r, j}^{\text {out }}=F_{a b s 1, j}^{\text {in }}+F_{b 1, j}^{\text {in }} \quad \forall j \in J
\end{gathered}
$$

$$
F_{a b s 1, j}^{\text {out }}+F_{b 1, j}^{\text {out }}=F_{p s a 1, j}^{\text {in }}+F_{b 2, j}^{\text {in }} \quad \forall j \in J
$$

355 where $F_{b j}^{i n}$ and $F_{b j}^{\text {out }}$ are the inlet and outlet molar flows of component $j$ in bypass $b$. 356 The subscripts $r r$, $a b s 1, b 1, p s a 1$ and $b 2$ stand for the reformer reactor, first $\mathrm{CO}_{2}$ 
absorber, first bypass, $\mathrm{H}_{2}$ PSA and second bypass. Note that in cases where a stream division occurs, a composition mass balance has to be included in order to maintain the composition of the original stream. However, in this case, since the absorber/PSA cost, emission and separation only depends on the main component and both streams converge again before entering the next process unit, the composition mass balance can be skipped and thus the associated nonlinearities are avoided.

The stream then arrives at the main CO separation section. The next equation ensures that only one of the separation technologies is selected:

$$
y_{p s a 2}+y_{c d}+y_{a b s c o} \leq 1
$$

where psa2, cd and absco stand for the CO PSA, cryogenic distillation and CO absorption units. The mass balance is as follows:

$$
F_{p s a 1, j}^{o u t}+F_{b 2, j}^{o u t}=F_{p s a 2, j}^{i n}+F_{c d, j}^{i n}+F_{a b s c o, j}^{\text {in }} \quad \forall j \in J
$$

These units are also modelled using Eqs.(10)-(17). Since only one separation unit can exist, there is no real division, hence the composition mass balance is again avoided. Before the obtaining of the product, an additional $\mathrm{CO}_{2}$ removal step is added in case too much of the gas remains with it. Finally, the product $\mathrm{CO}$ is obtained at $>99 \%$ purity as the sum of the $\mathrm{CO}$ rich side draws of these units:

$$
F_{j}^{\text {product }}=F_{c d, j}^{C O}+F_{a b s c o, j}^{C O}+F_{p s a 2, j}^{C O} \quad \forall j \in J
$$

where $F_{j}^{\text {product }}$ is the molar flow of the product stream in $\mathrm{kmol} / \mathrm{h}$.

\subsubsection{Side draw management}

The side draws of all these separation units are split or mixed depending on their composition (Table 5). The $\mathrm{CO}_{2}$ draws obtained in the $\mathrm{CO}_{2}$ absorbers can be used as a 
raw material in the RWGS reactor, any of the $\mathrm{CO}_{2}$-consuming methane reforming processes or just stored. On the other hand, there are two different $\mathrm{H}_{2}$ draws: the $\mathrm{H}_{2}$-rich streams obtained in the cryogenic distillation and CO absorber units and the fuel cell grade almost pure $\mathrm{H}_{2}$ stream obtained in the first PSA. The fuel cell operates using $\mathrm{H}_{2}$ exclusively extracted in the first PSA (fuel cell grade $\mathrm{H}_{2}$ stream). In addition, the remaining $\mathrm{H}_{2}$ of this stream can enter the RWGS reactor, be used as fuel or become the byproduct. These three options are also available for the $\mathrm{H}_{2}$-rich streams. Furthermore, the $\mathrm{H}_{2}$-rich stream can be recycled back just before the first PSA choice, in case additional $\mathrm{H}_{2}$ has to be recovered. Therefore, the mass balances associated to the end uses of the side draws are as follows:

$$
\begin{aligned}
& \left(F_{i j}^{i n}-F_{i j}^{o u t}\right) \sum_{j} F_{i j d e}=\sum_{j}\left(F_{i j}^{i n}-F_{i j}^{o u t}\right) F_{i j d e} \\
& \forall j \in J, \forall(i, d) \in\left(I \times D^{\prime}\right) \wedge \forall(d, e) \in\left(D^{\prime} \times E^{\prime}\right)
\end{aligned}
$$

where the relations of unit $i$ and side draw $d\left(I \times D^{\prime}\right)$ and side draw $d$ and end use $e$ $\left(D^{\prime} \times E^{\prime}\right)$ are stablished in Table 4 and Table 5 .

Table 5. Side draws of the separation units and possible uses

\begin{tabular}{cc}
\hline Side draw $\boldsymbol{d}$ & End use $\boldsymbol{e}$ \\
\hline Water & waste \\
$\mathrm{CO}_{2}$ & syngas synthesis, RWGS reactor, storage \\
$\mathrm{H}_{2}$ pure & fuel cell, RWGS reactor, fuel gas, byproduct \\
$\mathrm{H}_{2}$-rich & recycle, RWGS reactor, fuel gas, byproduct \\
CO & product*
\end{tabular}


397 Heat integration (HI) is key in reducing the energetic demand in many chemical 398 processes, and in the case of syngas synthesis, it is particularly important. The high 399 temperatures needed in the synthesis are translated into a high energy demand, while such 400 demand derives into elevated costs and emissions. We integrate HI into the superstructure 401 using the transshipment problem approach [45], which is illustrated in Appendix B 402 (Figure B.1). This method consists in the division of the system hot $(h)$ and cold $(c)$ streams into stages ( $s t$ ) following the stream ordered temperatures (Table B.1). The temperatures of the hot streams are subtracted $\Delta T / 2$, while the opposite is done for the cold streams, where $\Delta T$ is the minimum temperature difference allowable for any heat transfer, which is set to $10^{\circ} \mathrm{C}$ in this work. Here, each stream exchanges heat in all stages that are included in its temperature range. The total hot utility $\left(Q_{h o t}, \mathrm{~kW}\right)$ heat flow the system needs enters on the first stage, while the total cold utility $\left(Q_{\text {cold }}, \mathrm{kW}\right)$ heat flow (Eqs. (25)-(27)).

$$
\begin{aligned}
& \sum_{H S Y N_{\text {syn, }, h}}\left(\Delta T_{1} F C p_{1 h} F_{\text {syn }, j^{\prime}}^{i n}\right)+\sum_{H R W G S_{\text {rugs }, h}}\left(\Delta T_{1} F C p_{1 h} F_{r w g s, j^{\prime}}^{\text {in }}\right)+Q_{h o t}= \\
& \sum_{C S Y N_{s y n, c}}\left(\Delta T_{1} F C p_{1 c} F_{s y n, j^{\prime}}^{i n}\right)+\sum_{C R W G S_{r v g s, c}}\left(\Delta T_{1} F C p_{1 c} F_{r w g s, j^{\prime}}^{i n}\right)+R_{1} \quad \forall j^{\prime} \in J \\
& \sum_{H S Y N_{s y n, h}}\left(\Delta T_{s t} F C p_{s t, h} F_{s y n, j^{\prime}}^{i n}\right)+\sum_{H R W G S_{r w g s, h}}\left(\Delta T_{s t} F C p_{s t, h} F_{r w g s, j^{\prime}}^{i n}\right)+R_{s t-1}= \\
& \sum_{C S Y N_{s y n, c}}\left(\Delta T_{s t} F C p_{s t, c} F_{s y n, j^{\prime}}^{i n}\right)+\sum_{C R W G S_{r w g s, c}}\left(\Delta T_{s t} F C p_{s t, c} F_{r w g s, j^{\prime}}^{i n}\right)+R_{s t} \\
& \forall j^{\prime} \in J, \forall s t \in S T \backslash\{1,|S T|\}
\end{aligned}
$$




$$
\begin{aligned}
& \sum_{H S Y N_{s y n, h}}\left(\Delta T_{|S T|} F C p_{|S T| h} F_{s y n, j^{\prime}}^{i n}\right)+\sum_{H R W G S_{r w g s, h}}\left(\Delta T_{|S T|} F C p_{|S T| h} F_{r w g s, j^{\prime}}^{i n}\right)+R_{|S T|-1}= \\
& \sum_{\operatorname{CSYN}_{\text {syn, }, c}}\left(\Delta T_{|S T|} F C p_{|S T| c} F_{\text {syn, } j^{\prime}}^{\text {in }}\right)+\sum_{C R W G S_{r v g s, c}}\left(\Delta T_{|S T|} F C p_{|S T| c} F_{r w s g, j^{\prime}}^{i n}\right)+Q_{\text {cold }} \quad \forall j^{\prime} \in J
\end{aligned}
$$

415 where $\Delta T_{s t}$ is the temperature increment in stage $s t, F C p_{s t, h}$ and $F C p_{s t, c}$ are the products 416 of the molar flows and heat capacities per $\mathrm{kmol} / \mathrm{h}$ of component $j^{\prime}\left(\mathrm{kW} \cdot \mathrm{h} \cdot{ }^{\circ} \mathrm{C} / \mathrm{kmol} j^{\prime}\right)$ 417 of hot stream $h$ and cold stream $c$ located at stage st and $H S Y N_{s y n, h}, C S Y N_{s y n, c}$, $418 H_{R W G} S_{r w g s, h}$ and $C R W G S_{r w g s, c}$ are the set relations between syngas synthesis technologies $419\left(S Y N_{i}\right)$ and RWGS reactor types $\left(R W G S_{i}\right)$ and the hot $h$ and cold $c$ streams (Eqs.(28) $-(31))$.

$$
\operatorname{CRWGS}_{r w g s, c}=\left\{\begin{array}{l}
(1, c 12),(1, c 13),(2, c 14),(2, c 15), \\
(3, c 16),(3, c 17),(4, c 18),(4, c 19)
\end{array}\right\}
$$

\subsubsection{Multi-objective optimization}

426

The objective functions selected for this study are the Specific Total Annualized Cost 427 (STAC) and the Global Warming Potential (GWP). The former is calculated as the sum of the annualized capital and operating costs of the process per kg of product CO:

$$
S T A C=\left(\sum_{i}\left(\text { AFCap }_{i}+o_{i}\right)+\operatorname{raw}_{j} \sigma_{j}\right) / F_{C O}^{\text {product }}
$$

$$
\operatorname{raw}_{j}=\sum_{\text {syn }} F_{\text {syn, }, j}^{\text {in }} \quad \forall j \in J \backslash\left\{C O_{2}\right\}
$$

$$
\operatorname{raw}_{\mathrm{CO}_{2}}=F_{\mathrm{CO}_{2}}^{e x}+\sum_{\text {syn }} F_{\text {syn, } \mathrm{CO}_{2}}^{\text {in }}
$$




$$
A F=\frac{I R(I R+1)^{\text {years }}}{(I R+1)^{\text {years }}-1}
$$

433

434

435

436

437

438

441

444

445

446

447

448

449

where $\operatorname{raw}_{j}(\mathrm{kmol} / \mathrm{h})$ is the raw material molar flow of component $j$ and $\sigma_{j}(\$ / \mathrm{kmol})$ is a parameter for calculating the cost of those raw materials. The variables $F_{\text {syn,j }}^{i n}$ and $F_{\mathrm{CO}_{2}}^{e x}$ $(\mathrm{kmol} / \mathrm{h})$ stand for the inlet molar flow of component $j$ and syngas synthesis technology syn and the additional $\mathrm{CO}_{2}$ molar flow that can be used in the RWGS reactor. To compute the annualization factor ( $A F$ ), the horizon time is 8 years and the interest rate ( $I R$ ) is set to 0.1 [46]. On the other hand, GWP includes the indirect emission of raw material and energy usage, as well as a term regarding the abatement of $\mathrm{CO}_{2}$ that is consumed in the system:

$$
\begin{aligned}
& G W P=\left[\begin{array}{c}
\sum_{\forall j \in J\left\{\left\{\mathrm{CO}_{2}\right\}\right.}\left(\operatorname{raw}_{j} \lambda_{j}\right)+\text { emission }^{f g}+\sum_{i} \text { emission }_{i}+ \\
+M_{\mathrm{CO}_{2}}\left(\sum_{\forall i \in\{a b s 1, a b s 2\}} \sum_{e}\left(F_{i j d e}\right)-r a w_{j}\right)
\end{array}\right] / F_{C O}^{\text {product }} \\
& j=\left\{C \mathrm{CO}_{2}\right\}, d=\left\{C \mathrm{O}_{2}\right\}
\end{aligned}
$$

442 where $\lambda_{j}$ is the GWP contribution of the raw materials $(\mathrm{kg} \mathrm{CO}$-eq $/ \mathrm{kmol} j)$.

443 The overall bi-MINLP formulation can be expressed in compact form as follows:

$$
\begin{gathered}
\min _{x, y}\{\operatorname{STAC}(x, y) ;-G W P(x, y)\} \\
\text { s.t. } \quad \text { constraints }
\end{gathered}
$$

where $x$ and $y$ stand for continuous generic variables associated with structural decisions. Solving this problem results in a set of Pareto alternatives that represent the optimal trade-off between the objectives. We used the $\varepsilon$-constraint method [13] to obtain these Pareto solutions by solving a set of instances of the following single-objective problem (M1) for different values of the auxiliary parameter $\varepsilon$ : 


$$
\min _{x, y}\{S T A C\}
$$

s.t. $\quad$ constraints

$$
\begin{aligned}
& G W P \leq \varepsilon \\
& \underline{\varepsilon} \leq \varepsilon \leq \bar{\varepsilon}
\end{aligned}
$$

451 Where $\underline{\varepsilon}$ and $\bar{\varepsilon}$ denote the lower and upper bounds of $\varepsilon$, which are obtained by 452 individually optimizing each objective. The minimization of the GWP directly results in 453 the value of $\underline{\varepsilon}$, while the minimization of the STAC provides $\bar{\varepsilon}$, since the lowest cost generates the higher emission:

455

456

457

458

459

460

461

462

463

464

465

466

467
(M1a)

$$
(\bar{x}, \bar{y})=\underset{x, y}{\arg \min }\{T A C\}
$$

s.t. constraints

$(M 1 b)$

s.t. constraints

\section{Results and discussion}

We optimize the superstructure fixing a molar flow value of the product CO of $0.1 \mathrm{kmol} / \mathrm{s}$. According to this, we bound the problem variables using Aspen HYSYS v9.0 simulations as a reference. Initialization is also carried out with these reference values. The model is comprised of 742 equations and 483 variables, 20 of which are binary variables. We used GAMS [47] and the ANTIGONE solver [48] to implement and solve the problem, respectively.

The main results of the multi-objective optimization problem are shown in Figure 3. Results are separated in different cases: a Base Case where a binary cut prevents the fuel cell and RWGS reactor from appearing in the final solution, Case 1 where the fuel cell is free to be selected, Case 2 where the RWGS reactors are available for selection and Case 3 where any feasible combination contained in the superstructure is a valid solution. 
470 Parting from the solutions of each individual case, the byproduct off-gas is then valorized

471 both economically and environmentally in two additional scenarios per case study: its

472 combustion and use as energy and its utilization as syngas outside the boundaries of the

473 system. The valorization as energy considers that it substitutes natural gas combustion,

474 hence, its selling cost is considered the same (9.237 \$/MWh [34]). On the other hand, its

$475 \mathrm{CO}_{2}$ emissions are calculated assuming total combustion of the gas minus the avoided

476 emissions of the same quantity of natural gas based energy would produce (212.2 $\mathrm{kg} \mathrm{CO} 2-$

477 eq/MWh [10]). Utilization as hydrogen/syngas is valorized using Eqs.(6)-(7) adjusted

478 from the economic and environmental values of syngas with $\mathrm{H}_{2} / \mathrm{CO}$ ratios of 1.0, 1.5, 2.0

479 and 2.5 in addition to considering the extreme cases where only $\mathrm{CO}\left(\mathrm{H}_{2} / \mathrm{CO}\right.$ ratio is zero)

480 or $\mathrm{H}_{2}$ is produced ( $\mathrm{H}_{2} / \mathrm{CO}$ assumed 100 or more) (Table A. 7).
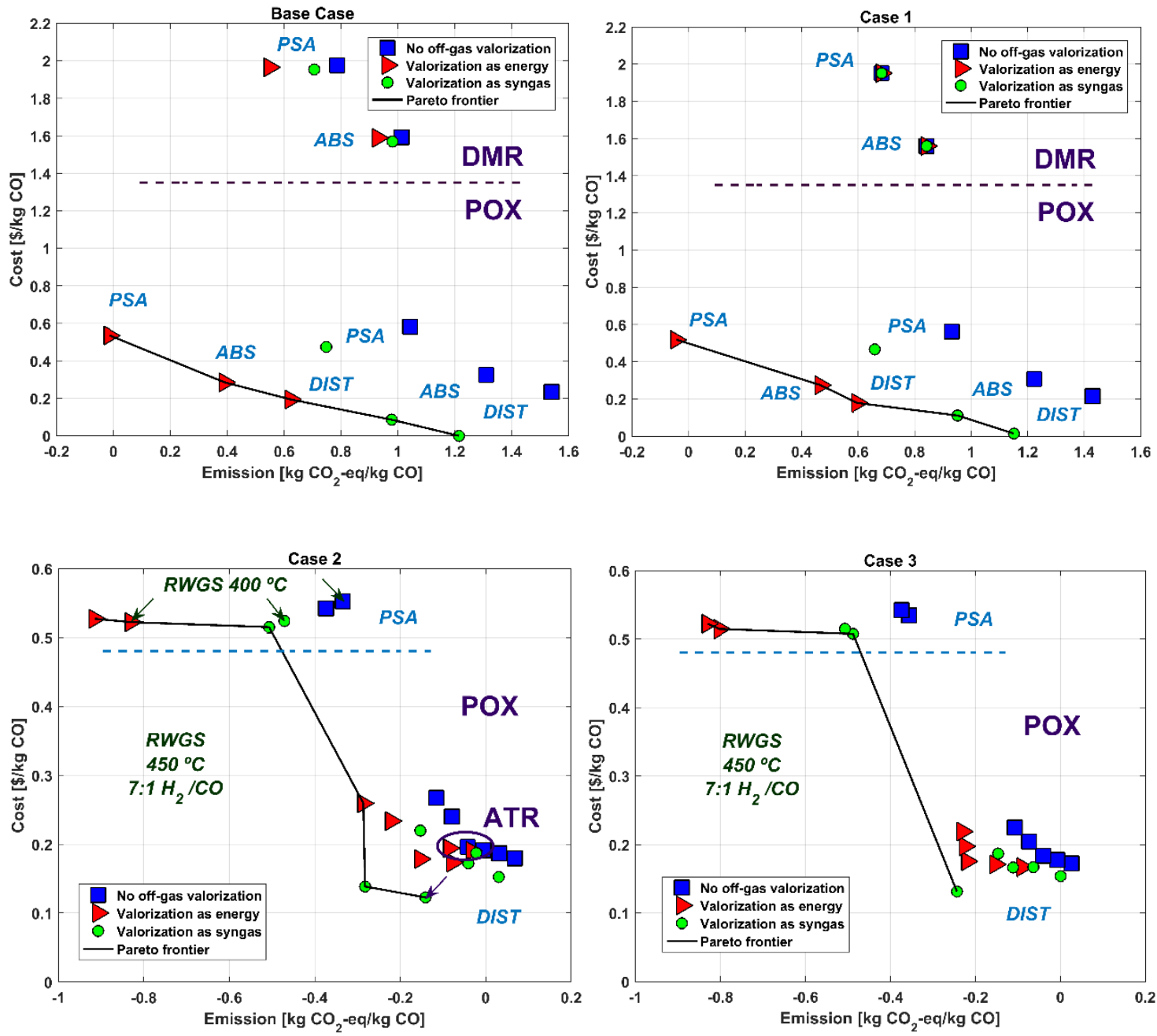

482 
Figure 3. Results of the multi-objective optimizations of the carbon monoxide synthesis proposed model. The employed syngas synthesis and separation technologies are included along with the RWGS reactor operating conditions in the applicable case scenarios.

\subsection{Base case studies (before off-gas valorization)}

The minimum cost solution of the base case scenario represents the classic CO synthesis and provides a reference solution in order to compare with other non-conventional configurations. The resulting emission $(1.54 \mathrm{~kg} \mathrm{CO}-\mathrm{eq} / \mathrm{kg})$ falls in the reported range (1.40 - $2.32 \mathrm{~kg} \mathrm{CO}$-eq $/ \mathrm{kg}[10])$ for CO synthesis, while the cost $(0.234 \$ / \mathrm{kg})$ is almost within it $(0.254-0.281 \$ / \mathrm{kg}[14])$, which reinforces the reliability of this result. The selected configuration consists of partial oxidation (POX) for the synthesis and cryogenic distillation as the main carbon monoxide separation technology, which matches with the most utilized syngas production and CO separation processes used industrially for this task $[20,26,27,29]$. This configuration is only natural since the minimum production costs sought at industrial level should be provided by the most used technologies. As the emission decreases (and the cost increases), the selected CO separation technology shifts to absorption, followed by adsorption (PSA) and when the production reaches its minimum emission values, the selected syngas synthesis process changes to Dry Methane Reforming (DMR). The emission can be decreased down to $0.786 \mathrm{~kg} \mathrm{CO}$ 2-eq/kg CO (49 $\%$ reduction) but the cost rises dramatically, almost tenfold. On the one hand, the shift in separation technology can be mainly explained with each process energy demands. Absorption suffers from significant operating costs due to solvent regeneration and usage while PSA requires an elevated electricity supply in addition to its high capital cost [32]. However, neither of these technologies relies on the use of a high emitting refrigerant like cryogenic distillation does, resulting in overall less emitting processes despite the 
meaningful energy requirement. On the other hand, DMR has been proven to net consume $\mathrm{CO}_{2}$ when producing low $\mathrm{H}_{2} / \mathrm{CO}$ syngas ratios [11], which explains its usage in the minimum emission solutions for $\mathrm{CO}$ synthesis, which is technically the lowest $\mathrm{H}_{2} / \mathrm{CO}$ syngas ratio. However, the high endothermicity of its main reaction results in elevated production costs due to a significant energy demand.

Results of the inclusion of the fuel cell in Case 1 show a positive effect since both cost and emission objectives are overall moderately reduced, specially the latter. The clean electricity produced by the fuel cell undeniably reduces the emissions, however, this reduction is damped by the additional effort required to separate and achieve the fuel cell grade purity $\mathrm{H}_{2}$. The cost, on the other hand, is barely affected in comparison to the base case. Fuel cell electricity is notorious for its higher cost compared to the traditional power plant supply, which is mainly related to the obtaining of hydrogen. In this case study, and even though it requires purification, $\mathrm{H}_{2}$ is but a byproduct of $\mathrm{CO}$ production. This means that a steady supply of the gas is available without specifically synthesizing it, which is translated into a less expensive fuel cell electricity production.

As shown in Case 2 results (Figure 3), the inclusion of a RWGS reactor drastically reduces both cost and emission, even below the carbon neutrality barrier. The RWGS reaction takes advantage of the surplus $\mathrm{H}_{2}$ and consumes $\mathrm{CO}_{2}$ in order to form water and CO. The consequences of this are twofold: first, the high consumption of $\mathrm{CO}_{2}$ greatly reduces the overall GWP of the process; and second, the additional CO production in the RWGS reactor reduces raw material and energy demand in the reforming section, along with their associated cost and emission. Regarding the technology selection for the synthesis, Auto-thermal Reforming (ATR) appears as one of the minimum cost solutions additionally to POX, while DMR disappears from the minimum emission solutions. POX and ATR are closely related. Not only do they use similar raw materials, produce similar 
$533 \mathrm{H}_{2} / \mathrm{CO}$ ratio syngas and possess high exothermicity but also they are the two most used

534

535 syngas synthesis processes precisely for this very reason. The absence of DMR in the minimum emission solution is explained by the inclusion of the RWGS reactor. The RWGS reaction requires $\mathrm{H}_{2}$, however, DMR produces around half the quantity provided by POX and ATR. This fact makes the latter processes more suitable to work with the RWGS reactor than DMR, while the role of the $\mathrm{CO}_{2}$ consuming process is adopted by the former. The selected separation technology in the minimum cost scenario is again cryogenic distillation, while the minimum emission results require PSA. Case 3 results in the combination of Case 1 and 2, where the moderate reduction in cost and emission of the former adds up to the high effect of the latter, in the overall best case scenario.

\subsection{Off-gas valorization}

The off-gas composition as well as the potential energy produced in its combustion process are shown in Figure 4 and Figure 5, respectively. The base case scenario Pareto frontier after byproduct valorization is shown in Figure 3. Valorization as syngas holds the minimum cost results while the use as energy is preferred in order to achieve the lowest emission values. Note that the minimum production cost after off-gas valorization as syngas is close to zero. This is due to the byproduct composition being mainly $\mathrm{H}_{2}$ with barely no CO (Figure 4). It is clear that syngas and hydrogen are relevant products with many applications and the manufacture of such valuable byproducts can economically overshadow the main product yield. However, even if CO is theoretically less valuable than $\mathrm{H}_{2}$, its production is still mandatory in the chemical industry so as to synthesize a wide range of value added products (Figure 1). 

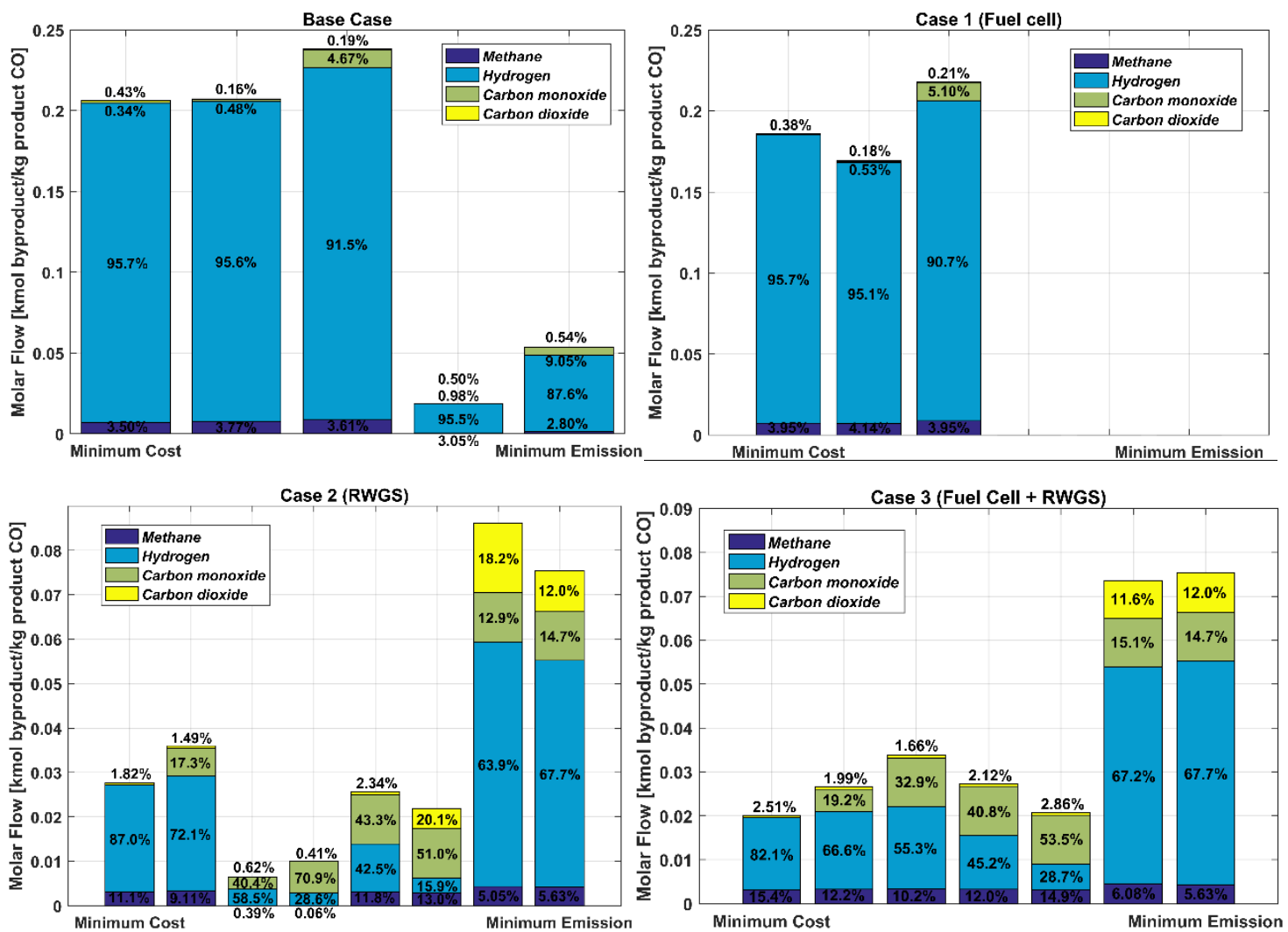

Figure 4. Off-gas byproduct stream molar flows and compositions (Figure 3).

Compositions from bottom to top: methane, hydrogen, carbon monoxide and carbon dioxide.

This hydrogen rich off-gas has another important feature. When producing energy, the associated emission is way lower than that of natural gas combustion. This translates into

562 a more than appreciable $\mathrm{CO}_{2}$ abatement when substituting the fuel, with results slightly below carbon neutrality, even though no $\mathrm{CO}_{2}$ consumption is achieved in the related process configuration. Case 1 results are again similar compared to the base case.

565 However, the most striking difference is not in the main results (Figure 3) but the in the off-gas production (Figure 4), where the overall quantity of byproduct is reduced as effect

567 of the fuel cell usage due to the off-gas being mainly composed of $\mathrm{H}_{2}$. Furthermore, this

568 reduction is increasingly marked at lower emission configurations, to the point where there is no byproduct production whatsoever. This decreasing off-gas yield at minimum 

increases hot utility consumption in comparison with POX. Therefore, less or even no off-gas is produced due to its use as a fuel inside the system boundaries. This behavior is reflected in the energy production (Figure 5), since it is closely related to the off-gas yield.
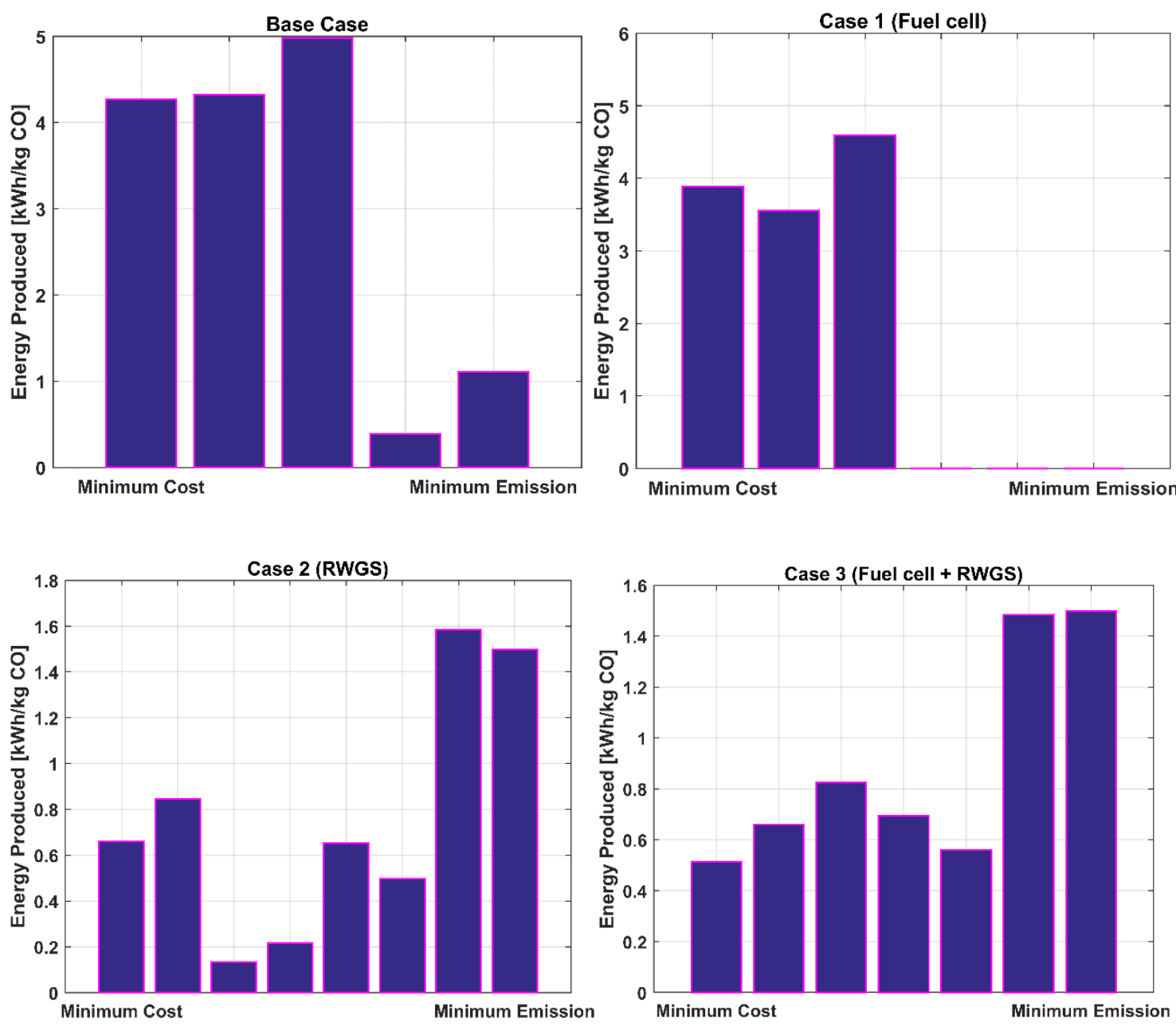

Figure 5. Energy produced when valorizing the off-gas in the synthesis of CO (Figure 3).

577 Although production costs after valorization are still lower in the first two case studies,

578 results located in the Pareto frontier of Case 2 and 3 are situated well below the carbon

579 neutrality barrier (Figure 3). Note that both the minimum cost and minimum emission

580 solutions of Case 2 are lower than those of Case 3, even though the latter possesses the

581 additional feature of the fuel cell that should result in the opposite. The fuel cell consumes

582 some of the off-gas in order to produce energy, reducing the overall byproduct yield. 
583 Before valorization, this extra consumption has a positive effect in both objectives, 584 however, after valorization, the reduced off-gas production is noticeable as the byproduct 585 cost and emission input is lower, resulting in slightly best cases overall when only the 586 RWGS reactor is considered (Case 2).

587 Overall off-gas compositions (Figure 4) in the first two cases where no RWGS reactor is 588 involved are hydrogen rich, with $\mathrm{H}_{2} / \mathrm{CO}$ ratios well over 100 and only two cases being slightly below 20. This off-gas can be utilized in ammonia synthesis, process that already possesses a syngas to $\mathrm{H}_{2}$ upgrading (water gas shift reaction, WGS) and $\mathrm{CO}_{2}$ /methane separation system [49]. The addition of the RWGS reactor (Case 2 and 3) evens out the ratios, especially in the intermediate area where cost and emission are neither minimum nor maximum. Many of these ratios revolve around the value of two, which is the optimal composition for methanol and Fischer-Tropsch synthesis [50,51]. This syngas would be especially useful in acetic and formic acid synthesis where the raw materials needed for the most relevant synthesis routes are carbon monoxide and methanol [5,7], making these three processes perfectly integrable.

\subsection{Carbon dioxide consumption}

The consumption of $\mathrm{CO}_{2}$ for the production of $\mathrm{CO}$ in all case studies is shown in Figure

6. In the first two case studies (no RWGS inclusion), the minimum cost points are situated below the zero consumption mark, which is equivalent to net production of $\mathrm{CO}_{2}$. These solutions use POX (Figure 3) as their syngas reforming technology, which is not a $\mathrm{CO}_{2}$ utilizing process (in fact, it is produced in the reaction). As emission decreases, $\mathrm{CO}_{2}$ consumption soars to $0.8-0.9 \mathrm{~kg} \mathrm{CO}$-eq $/ \mathrm{kg}$, which is the consequence of using DMR 
607 Note that consumption steadily increases up to $1.1 \mathrm{~kg} \mathrm{CO}$-eq $/ \mathrm{kg}$ before falling again 608 between the range of $0.8-0.9 \mathrm{~kg} \mathrm{CO}$-eq $/ \mathrm{kg}$. This behavior may seem contradictory but 609 it actually highlights a paramount matter: maximizing $\mathrm{CO}_{2}$ consumption is not 610 necessarily the best solution when the objective of a study is the reduction of the overall 611 emission of a process. This is the reason why the GWP indicator, that not only considers $612 \mathrm{CO}_{2}$ consumption but also indirect $\mathrm{CO}_{2}$ emissions of other sources, is the best choice when tackling a $\mathrm{CO}_{2}$ consumption study.

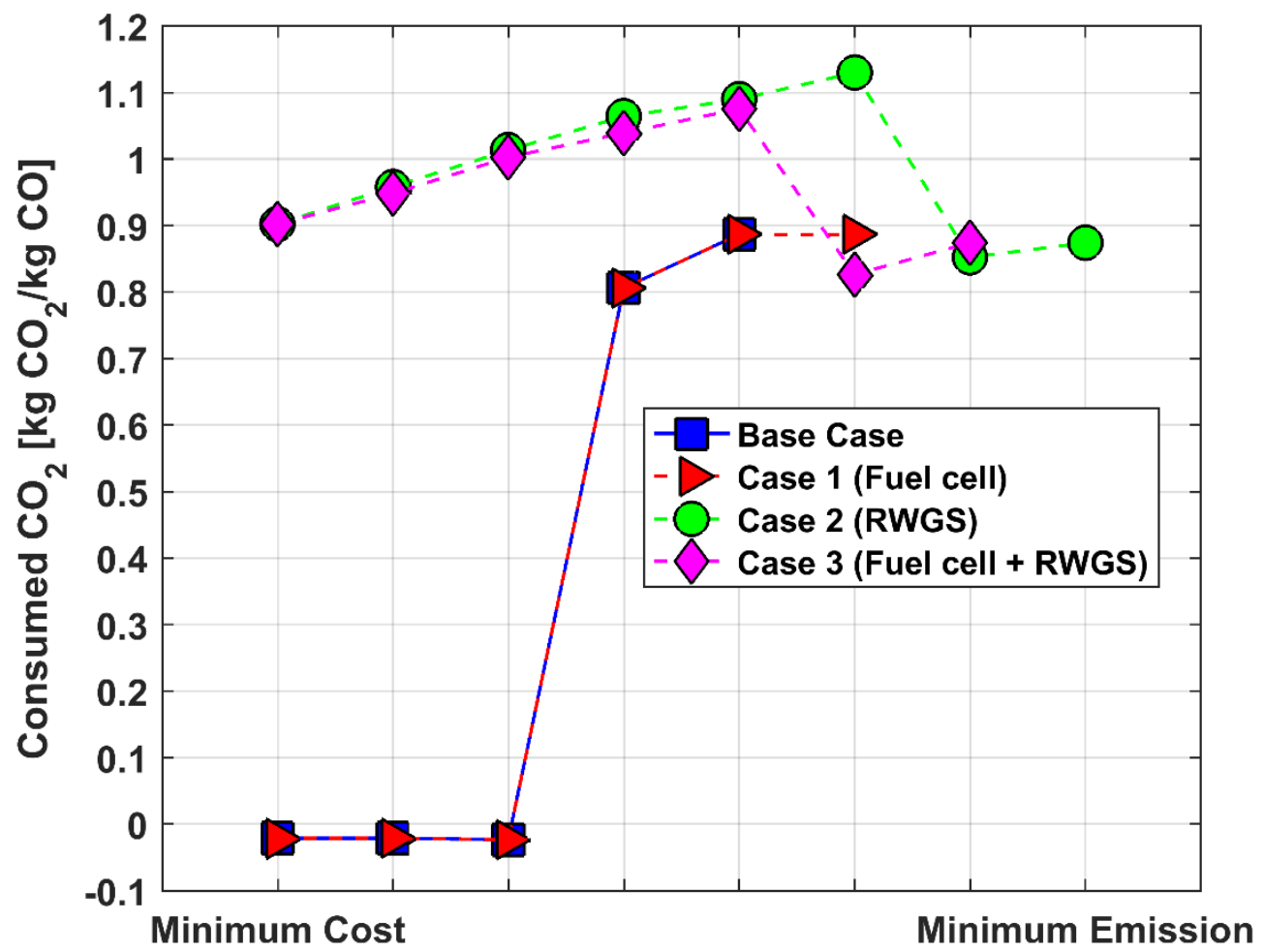

Figure 6. Carbon dioxide consumption in the synthesis of CO.

\section{Conclusions}

617 Carbon monoxide synthesis and separation is a key step in the production of many important bulk chemicals. This operation generates an off-gas byproduct which is often hydrogen rich and ends up being used as fuel. In this work, we propose a process superstructure in which different synthesis and separation technologies, alternative 
621 hydrogen utilization pathways and the possibility of consuming $\mathrm{CO}_{2}$ in the process of 622 carbon monoxide synthesis are considered. The results show that the minimum cost $(0.23$ $623 \$ / \mathrm{kg} \mathrm{CO}, 1.54 \mathrm{~kg} \mathrm{CO}$-eq/kg CO) configuration (classic synthesis) requires partial 624 oxidation of methane (POX) and cryogenic distillation as the carbon monoxide synthesis 625 and separation technologies. On the other hand, when minimizing the emission, dry 626 methane reforming (DMR) and pressure swing adsorption (PSA) are the chosen 627 technologies, which achieve almost a $50 \%$ reduction in GWP but increase the cost about ten times compared to the base case. The inclusion of a fuel cell as an alternative hydrogen sink reduces the overall cost and emission of the synthesis. Furthermore, adding a reverse water gas shift (RWGS) reactor that consumes $\mathrm{H}_{2}$ and $\mathrm{CO}_{2}$ while simultaneously producing $\mathrm{CO}$, results in a drastic reduction of the GWP (up to $1.9 \mathrm{~kg} \mathrm{CO}_{2}$-eq reduction per kg CO compared to the base case) and cost (close to $30 \%$ in the best case), in addition to achieving a $\mathrm{CO}_{2}$ consumption varying between 0.8 and $1.1 \mathrm{~kg} \mathrm{CO} / \mathrm{kg} \mathrm{CO}$. The effect of byproduct valorization further improves the results. The economic objective reaches its minimum value when valorizing the byproduct as hydrogen/syngas, while emission is minimum if the off-gas is used to produce energy, long surpassing the carbon neutrality barrier (-0.83 kg CO 2 -eq per kg CO).

\section{Acknowledgements}

639 The authors gratefully acknowledge financial support to the Spanish «Ministerio de 640 Economía, Industria y Competitividad» under project CTQ2016-77968-C3-2-P 641 (AEI/FEDER, UE). The authors would also like to thank «Generalitat Valenciana: 642 Conselleria de Educación, Investigación, Cultura y Deporte» for the Ph.D grant 643 (ACIF/2016/ 062). 


\section{Appendix A.}

646

647

648

649

650

651

652

653

654

655

656

- Data and calculated parameters used in the optimization

$$
\text { See Table A.1 - Table A. } 7 .
$$

\section{Appendix B.}

- Heat integration.

See Figure B.1 and Table B.1.

\section{Appendix C.}

- Relevant results of the multi-objective optimizations

- $\quad$ See Figure C.1 - Figure C.4 and Table C.1 - Table C.4

\section{APPENDIX A}

Table A.1. Raw material cost $\left(\sigma_{j}\right)$ and emission $\left(\lambda_{j}\right)$ parameters used in the calculations of the syngas synthesis section of the model [11].

\begin{tabular}{cccc}
\hline Raw material & Source & $\sigma_{j}$ [\$/kg] & $\lambda_{j}$ [kg CO $\mathbf{~ - e q / k g ] ~ [ 1 0 ] ~}$ \\
\hline Methane & Global market (96\% volume) & $0.2441[34]$ & 0.7038 \\
Steam & Global market (chemical industry) & $0.0100[44]$ & 0.1830 \\
Oxygen & Cryogenic air separation unit & $0.1550[52]$ & 0.6304 \\
Carbon dioxide & Amine absorption & $0.0431[35]$ & 1.0000 \\
\hline
\end{tabular}

657

658 Table A.2. Fixed $c_{i k}^{f}$ and variable $c_{i k}^{v}$ cost parameters of process unit $i$ and type $k$ used in 659 Eq.(10) [11].

$$
\text { Unit } \quad C_{i k}^{f} \cdot \mathbf{1 0}^{-4}[\$] \quad C_{i k}^{v}[\$ / \text { capacity units] }
$$




\begin{tabular}{ccc}
\hline Compressor & 10.43 & 172.4 \\
Heat exchanger & 1.871 & 59.99 \\
Reformer furnace & 48.01 & 67.64 \\
Process vessel* & 1.531 & 314.1 \\
Fuel cell [41] & - & $7.789 \cdot 10^{4}$ \\
\hline
\end{tabular}

662 Table A.3. Process utility u cost ( $\left.\varphi_{u}\right)$ and emission $\left(\theta_{u}\right)$ used in Eqs.(16) and (17) [10].

\begin{tabular}{cccc}
\hline Utility & Source & $\varphi_{u}[\mathbf{S} / \mathbf{k W h}]$ & $\left.\theta_{u} \mathbf{~} \mathbf{k g} \mathbf{C O} \mathbf{2}-\mathbf{e q} / \mathbf{k W h}\right]$ \\
\hline Natural gas & Heat production at industrial furnace & $0.0092[34]$ & 0.2122 \\
Cooling water & Process cooling water $\left(30^{\circ} \mathrm{C}\right.$ to 40 or $\left.45^{\circ} \mathrm{C}\right)$ & $0.0013[44]$ & - \\
Electricity & High voltage & $0.1305[53]$ & 0.4473 \\
\hline
\end{tabular}

663

664 Table A.4. Utility $u$ consumption $\left(a_{i u}\right)$ in process unit $i$ and additional utility consumption $\left(b_{i}\right)$ binary parameter in process unit i used in Eqs.(16) and (17).

\begin{tabular}{|c|c|c|c|c|}
\hline \multirow[b]{2}{*}{ Process unit / Utility } & \multicolumn{3}{|c|}{$a_{i u}\left[\mathbf{k W h} / \mathbf{k m o l} j^{\prime}\right]$} & \multirow{2}{*}{$\begin{array}{c}b_{i} \\
\text { Additional }\end{array}$} \\
\hline & Natural gas & Cooling water & Electricity & \\
\hline Phase separator & - & - & - & - \\
\hline $\mathrm{CO}_{2}$ absorber & - & - & - & 1 \\
\hline PSA H $_{2}$ & - & - & $*$ & - \\
\hline Cryogenic distillation & - & - & - & 1 \\
\hline CO absorber [32] & 11.64 & 0.622 & 6.402 & 1 \\
\hline PSA CO & - & - & $*$ & 1 \\
\hline Fuel cell & - & - & - & - \\
\hline RWGS1 reactor & 18.90 & - & - & - \\
\hline RWGS2 reactor & 26.00 & - & - & - \\
\hline
\end{tabular}


RWGS3 reactor

RWGS4 reactor
32.96

37.29

$666 *$ Note that the electricity consumption is calculated before the PSA units and hence it is

667 instead included in the cost and emission of the synthesis gas generation [11]:

668

$$
\begin{aligned}
& \text { power }_{i}=\left(\frac{\gamma}{\gamma-1}\right) \eta^{-1} R_{g} T \sum_{j} F_{i j}^{i n}\left[\left(\frac{P_{i}}{P}\right)^{\left(\frac{\gamma}{\gamma-1}\right)}-1\right] \\
& \forall i \in\{\text { syngas synthesis }\}
\end{aligned}
$$

669

where power $_{i}$ is the electricity consumption, $\gamma$ is the capacity ratio fixed at $1.5, \eta$ is the

670 compressor efficiency fixed at $0.8, R_{g}$ is the universal gas constant in $\mathrm{kJ} /(\mathrm{kmol} \cdot \mathrm{K}), T$ is

671 the inlet temperature $\left(40{ }^{\circ} \mathrm{C}\right), P_{i}$ is the working pressure of the synthesis gas reforming

672 technology and $P$ is the inlet pressure of the separation technologies (30 bar).

673

Table A.5. Emission $\left(\psi_{i}\right)$ and cost $\left(\omega_{i}\right)$ of additional utilities or combination of utilities

674 in process unit $i$ used in Eqs.(16) and (17).

\begin{tabular}{ccc}
\hline Process unit & $\omega_{i}\left[\mathbf{\$} / \mathbf{k m o l} j^{\prime}\right]$ & $\psi_{i}\left[\mathbf{k g ~ C O}\right.$-eq/kmol $\left.j^{\prime}\right]$ \\
\hline Phase separator & - & - \\
CO $_{2}$ absorber* [35] & 1.896 & 0.040 \\
PSA H 2 & - & - \\
Cryogenic distillation* & $1.991[29]$ & $16.44[33]$ \\
CO absorber** & $3.976[32]$ & $7.711[10,32]$ \\
PSA CO*** & $0.271[32]$ & - \\
Fuel cell & - & - \\
RWGS1 reactor & - & - \\
RWGS2 reactor & - & - \\
RWGS3 reactor & - & - \\
RWGS4 reactor & - & - \\
\hline
\end{tabular}


676

677

678

679

680

681

682 683 used in Eq.(15).

\begin{tabular}{cccc}
\hline & Phase separator & $\mathrm{CO}_{2}$ absorption & $\mathrm{H}_{2}$ PSA \\
\hline & Water & $\mathrm{CO}_{2}$ & $\mathrm{H}_{2}$ pure \\
\hline $\mathrm{CH}_{4}$ & - & - & - \\
$\mathrm{H}_{2}$ & - & - & 0.90 \\
$\mathrm{CO}$ & - & 0.96 & - \\
$\mathrm{CO}_{2}$ & - & - & - \\
$\mathrm{H}_{2} \mathrm{O}$ & 1.00 & - & - \\
\end{tabular}

684

\begin{tabular}{ccccccccc}
\hline & \multicolumn{2}{c}{ Cryogenic distillation } & \multicolumn{3}{c}{ CO absorption } & \multicolumn{2}{c}{ CO PSA } \\
\hline & $\mathbf{H}_{2}$-rich & Off-gas & $\mathbf{C O}$ & $\mathbf{H}_{2}$-rich & Off-gas & $\mathbf{C O}$ & $\mathbf{H}_{2}$-rich & $\mathbf{C O}$ \\
\hline $\mathbf{C H}_{4}$ & $0.95-0.05$ & - & - & $0.95-0.05$ & - & - & $0.95-0.05$ & - \\
$\mathbf{H}_{2}$ & $0.95-0.90$ & - & - & $0.95-0.90$ & - & - & $0.95-0.90$ & - \\
$\mathbf{C O}$ & - & - & 0.90 & - & - & 0.99 & - & 0.99 \\
$\mathbf{C O}_{2}$ & $0.95-0.05$ & - & - & $0.95-0.05$ & - & - & $0.95-0.05$ & - \\
$\mathbf{H}_{2} \mathbf{O}$ & - & - & - & - & - & - & - & - \\
\hline
\end{tabular}

685

686 Table A. 7. Syngas cost and emission $\mathrm{H}_{2} / \mathrm{CO}$ molar ratio dependence used for correlating 687 Eqs.(6)-(7) [11].

\begin{tabular}{ccc}
\hline $\mathbf{H}_{2} / \mathbf{C O}$ molar ratio & Cost [\$/kg] & GWP [kg CO 2 -eq/kg] \\
\hline 0.0 & $0.254[14]$ & $1.859[10]$
\end{tabular}




$\begin{array}{ccc}1.0 & 0.144 & 0.599 \\ 1.5 & 0.140 & 0.581 \\ 2.0 & 0.136 & 0.588 \\ 2.5 & 0.154 & 0.874 \\ <100 & 1.580 & 2.192[10]\end{array}$

688

689

690

APPENDIX B

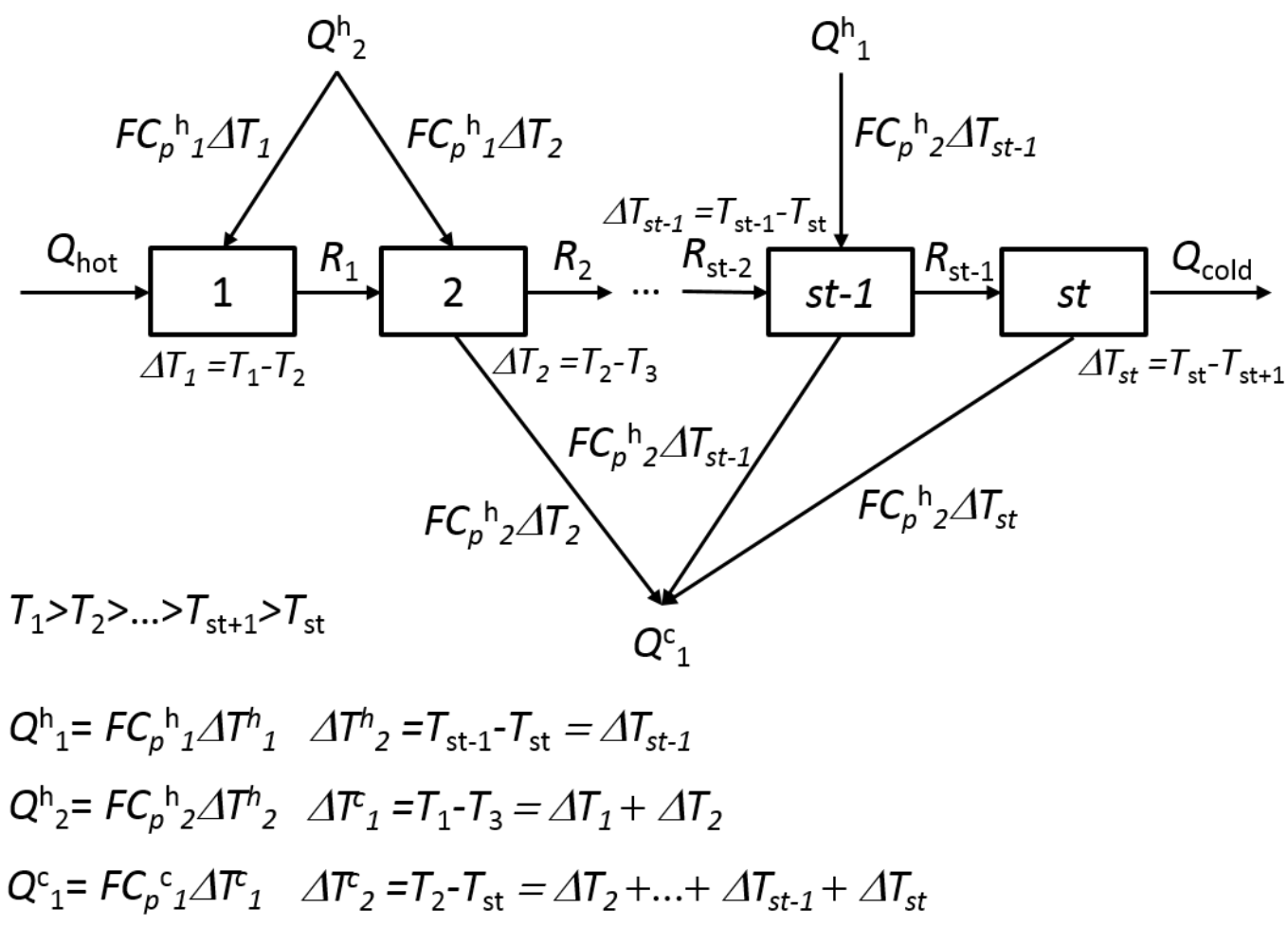

691

692

693

Figure B.1. Transshipment problem [45] general example supporting the description of section 2.4.3. Increments of temperature are taken arbitrarily.

694

695 Table B.1. Stream information for the transshipment problem in the proposed 696 superstructure (Eqs.(25)-(27)).

\begin{tabular}{ccccc}
\hline Stream & Process & $\mathbf{T}_{\text {in }}\left[{ }^{\circ} \mathbf{C}\right]$ & $\left.\mathbf{T}_{\text {out }}{ }^{\mathbf{0}} \mathbf{C}\right]$ & $\mathbf{F C}_{\mathbf{p}}\left[\mathbf{k W} \cdot \mathbf{h} /{ }^{\circ} \mathbf{C} \cdot \mathbf{k m o l} j^{\prime}\right]$ \\
\hline h1 & SMR & 900 & 40 & 216 \\
h2 & POX & 1197 & 40 & 99.5
\end{tabular}




\begin{tabular}{|c|c|c|c|c|}
\hline Stream & Process & $\mathbf{T}_{\text {in }}\left[{ }^{\circ} \mathrm{C}\right]$ & $\mathbf{T}_{\text {out }}\left[{ }^{\circ} \mathbf{C}\right]$ & $\mathrm{FC}_{\mathrm{p}}\left[\mathrm{kW} \cdot \mathrm{h} /{ }^{\circ} \mathrm{C} \cdot \mathrm{kmol} j^{\prime}\right]$ \\
\hline h3 & ATR & 1231 & 40 & 171 \\
\hline h4 & CR & 830.7 & 830.6 & 885 \\
\hline h5 & CR & 830.7 & 40 & 196 \\
\hline h6 & DMR & 850 & 40 & 129 \\
\hline h7 & BR & 850 & 40 & 193 \\
\hline h8 & TR & 827 & 40 & 271 \\
\hline h9 & TR & 827 & 826.9 & 237 \\
\hline h10 & RWGS1 & 300 & 40 & 238 \\
\hline h11 & RWGS2 & 350 & 40 & 238 \\
\hline h12 & RWGS3 & 400 & 40 & 238 \\
\hline h13 & RWGS4 & 450 & 40 & 238 \\
\hline c1 & SMR & 900 & 167.6 & 265 \\
\hline c2 & SMR & 900 & 899.9 & 1970 \\
\hline c3 & POX & 800 & 213.9 & 62.2 \\
\hline c4 & ATR & 750 & 151.7 & 160 \\
\hline c5 & CR & 850 & 171.4 & 230 \\
\hline c6 & CR & 850 & 849.9 & 1570 \\
\hline c7 & DMR & 850 & 40 & 74.5 \\
\hline c8 & DMR & 850 & 849.9 & 2460 \\
\hline c9 & $\mathrm{BR}$ & 850 & 211 & 138 \\
\hline c10 & BR & 850 & 849.9 & 2.2 \\
\hline c11 & TR & 827 & 142.8 & 282 \\
\hline c12 & RWGS1 & 300 & 40 & 249 \\
\hline c13 & RWGS1 & 300 & 299.9 & 45.8 \\
\hline c14 & RWGS2 & 350 & 40 & 248 \\
\hline c15 & RWGS2 & 350 & 349.9 & 176 \\
\hline c16 & RWGS3 & 400 & 40 & 247 \\
\hline c17 & RWGS3 & 400 & 399.9 & 300 \\
\hline c18 & RWGS4 & 450 & 40 & 248 \\
\hline
\end{tabular}




\begin{tabular}{ccccc}
\hline Stream & Process & $\mathbf{T}_{\text {in }}\left[{ }^{\mathbf{o}} \mathbf{C}\right]$ & $\mathbf{T}_{\text {out }}\left[{ }^{\mathbf{o}} \mathbf{C}\right]$ & $\mathbf{F C}_{\mathbf{p}}\left[\mathbf{k W} \cdot \mathbf{h} /{ }^{\circ} \mathbf{C} \cdot \mathbf{k m o l} j^{\prime}\right]$ \\
\hline c19 & RWGS4 & 450 & 449.9 & 328
\end{tabular}

697

698

699

\section{APPENDIX C}

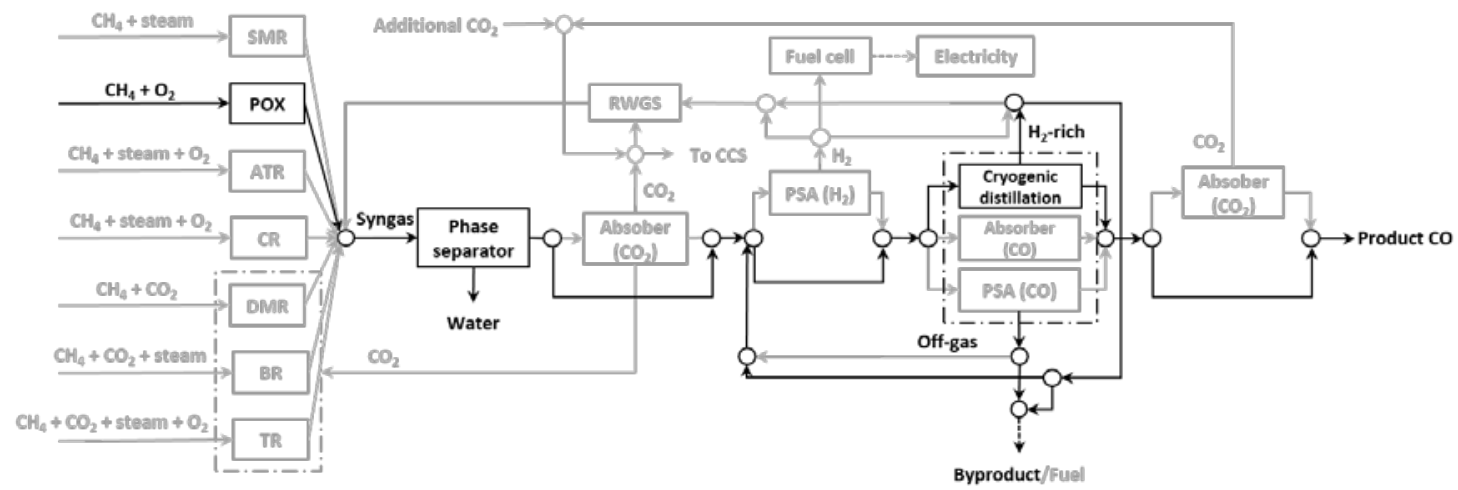

701

Figure C.1. Minimum cost Pareto result configuration of the Base Case multi-objective 702 optimization (Figure 3).

703

704

Table C.1. Molar flow results [kmol/s] of Figure C.1.

\begin{tabular}{cccccccc}
\hline & Feed & POX out & Flash out & CD in & H$_{2}$-rich & Byproduct & Product \\
\hline $\mathbf{C H}_{4}$ & 0.110 & 0.008 & 0.008 & 0.012 & 0.004 & 0.007 & 0.001 \\
$\mathbf{H}_{2} \mathbf{O}$ & - & 0.006 & - & - & - & - & - \\
$\mathbf{O}_{2}$ & 0.055 & - & - & - & - & - & - \\
$\mathbf{C O}_{2}$ & - & 0.001 & 0.001 & 0.008 & 0.008 & 0.001 & 0.000 \\
$\mathbf{H}_{2}$ & - & 0.198 & 0.198 & 1.249 & 1.125 & 0.198 & 0.000 \\
$\mathbf{C O}$ & - & 0.101 & 0.101 & 0.111 & 0.011 & 0.001 & 0.100 \\
\hline
\end{tabular}

705

706

707 
709

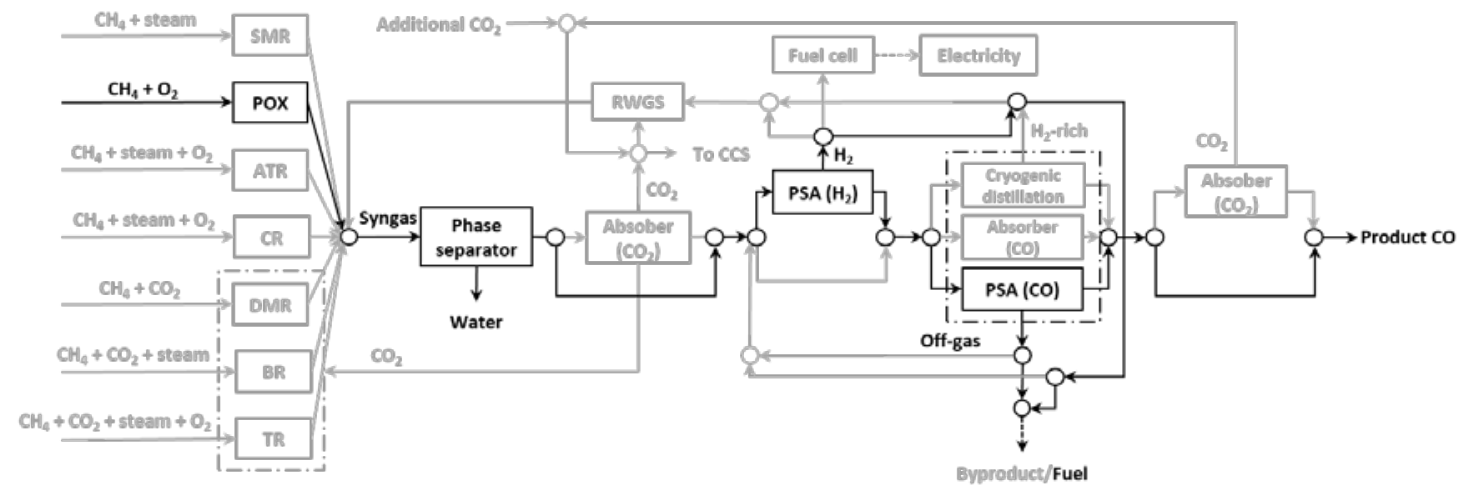

710

711

712

713

Table C.2. Molar flow results [kmol/s] of Figure C.2.

Figure C.2. Minimum emission Pareto result configuration of the Base Case multiobjective optimization (Figure 3).

\begin{tabular}{cccccccc}
\hline & Feed & POX out & Flash out & PSA (H $\mathbf{H}_{2}$ in & PSA (CO) in & Fuel gas & Product \\
\hline $\mathbf{C H}_{4}$ & 0.121 & 0.009 & 0.009 & 0.009 & 0.009 & 0.009 & 0.000 \\
$\mathbf{H}_{2} \mathbf{O}$ & - & 0.007 & - & - & - & - & - \\
$\mathbf{O}_{2}$ & 0.061 & - & - & - & - & - & - \\
$\mathbf{C O}_{2}$ & - & 0.001 & 0.001 & 0.001 & 0.001 & 0.000 & 0.001 \\
$\mathbf{H}_{2}$ & - & 0.218 & 0.218 & 0.218 & 0.022 & 0.218 & 0.000 \\
$\mathbf{C O}$ & - & 0.111 & 0.111 & 0.111 & 0.111 & 0.011 & 0.100 \\
\hline
\end{tabular}

714

715

716

717

718 
719

720

721

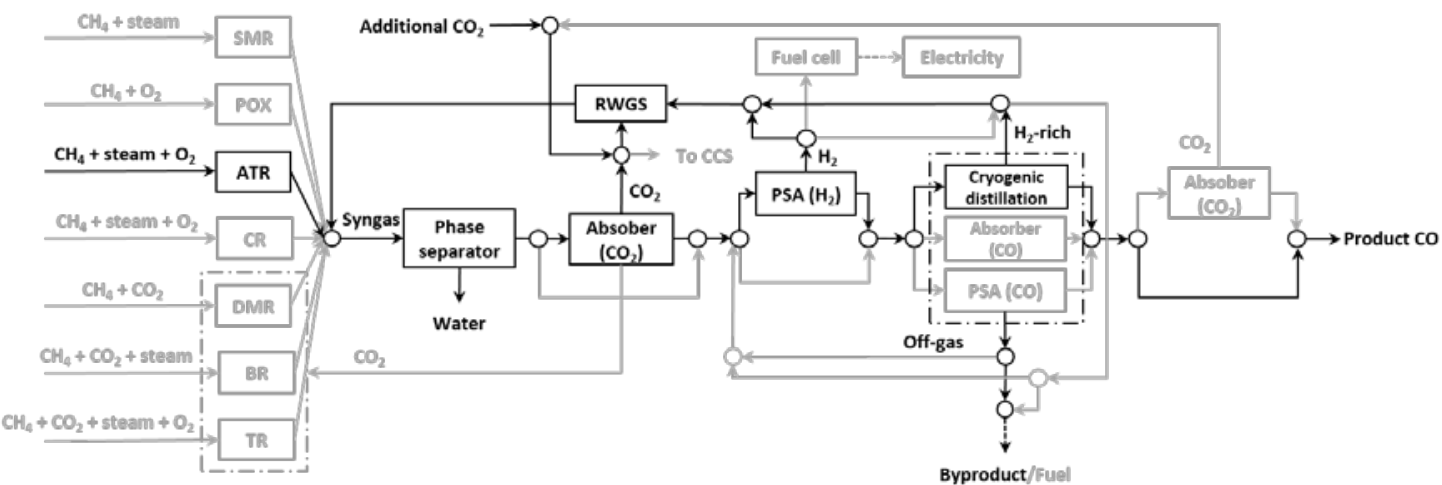

Figure C.3. Minimum cost Pareto result configuration of Case 2 (RWGS inclusion) multi-objective optimization (Figure 3).

722 Table C.3. Molar flow results $[\mathrm{kmol} / \mathrm{s}]$ of Figure C.3.

\begin{tabular}{cccccc}
\hline & Feed & ATR out & Flash out & PSA ( $\left.\mathbf{H}_{2}\right)$ in & CD in \\
\hline $\mathbf{C H}_{4}$ & 0.039 & 0.000 & 0.000 & 0.000 & 0.000 \\
$\mathbf{H}_{2} \mathbf{O}$ & 0.056 & 0.056 & 0.132 & - & - \\
$\mathbf{O}_{2}$ & 0.024 & - & - & - & - \\
$\mathbf{C O}_{2}$ & - & 0.008 & 0.021 & 0.000 & 0.000 \\
$\mathbf{H}_{2}$ & - & 0.079 & 0.623 & 0.623 & 0.062 \\
$\mathbf{C O}$ & - & 0.031 & 0.111 & 0.111 & 0.111
\end{tabular}

\begin{tabular}{ccccccc}
\hline & $\mathbf{H}_{2}$-rich & Byproduct & RWGS in & RWGS out & Add. CO 2 & Product \\
\hline $\mathbf{C H}_{4}$ & 0.000 & 0.000 & 0.000 & 0.000 & - & 0.000 \\
$\mathbf{H}_{2} \mathbf{O}$ & - & - & - & 0.076 & - & - \\
$\mathbf{O}_{2}$ & - & - & - & - & - & - \\
$\mathbf{C O}_{2}$ & 0.001 & 0.000 & 0.089 & 0.012 & 0.088 & 0.001 \\
$\mathbf{H}_{2}$ & 0.059 & 0.003 & 0.620 & 0.543 & - & 0.000 \\
$\mathbf{C O}$ & 0.004 & 0.007 & 0.004 & 0.080 & - & 0.100 \\
\hline
\end{tabular}




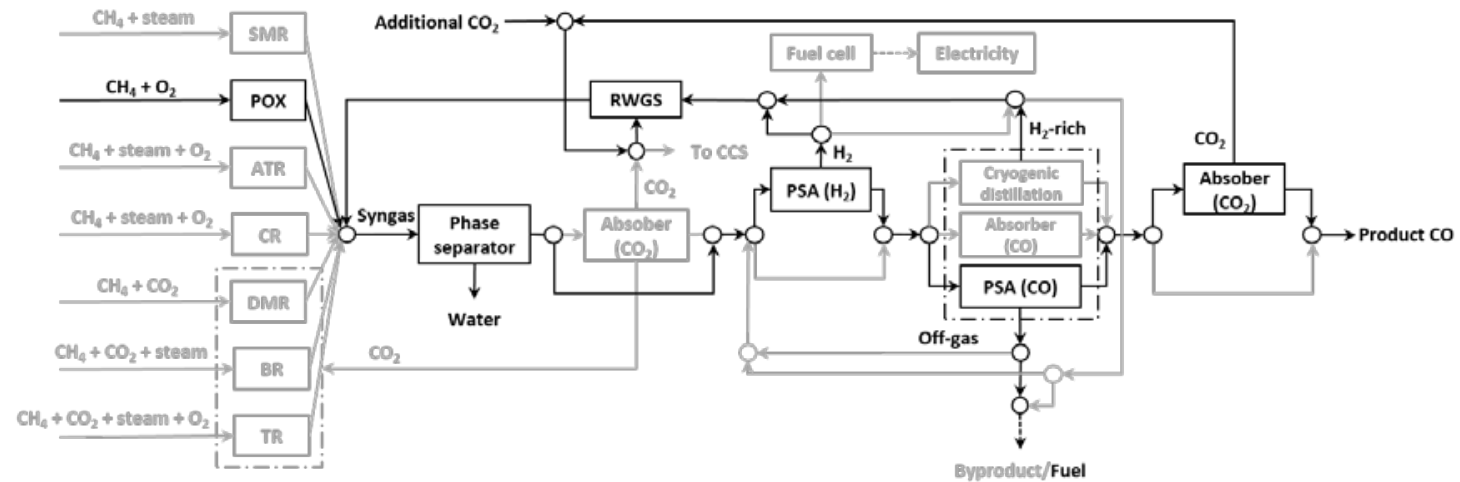

725

726

727

Table C.4. Molar flow results [kmol/s] of Figure C.4.

\begin{tabular}{|c|c|c|c|c|c|}
\hline & Feed & POX out & Flash out & PSA $\left(\mathrm{H}_{2}\right)$ in & PSA (CO) in \\
\hline $\mathrm{CH}_{4}$ & 0.060 & 0.004 & 0.004 & 0.004 & 0.004 \\
\hline $\mathrm{H}_{2} \mathrm{O}$ & - & 0.004 & - & - & - \\
\hline $\mathbf{O}_{2}$ & 0.060 & - & - & - & - \\
\hline $\mathrm{CO}_{2}$ & - & 0.001 & 0.010 & 0.010 & 0.010 \\
\hline $\mathbf{H}_{2}$ & - & 0.107 & 0.510 & 0.510 & 0.051 \\
\hline \multirow[t]{2}{*}{ CO } & - & 0.055 & 0.111 & 0.111 & 0.111 \\
\hline & Fuel gas & RWGS in & RWGS out & Add. $\mathrm{CO}_{2}$ & Product \\
\hline $\mathrm{CH}_{4}$ & 0.004 & 0.000 & 0.000 & - & 0.000 \\
\hline $\mathrm{H}_{2} \mathrm{O}$ & - & - & 0.056 & - & - \\
\hline $\mathbf{O}_{2}$ & - & - & - & - & - \\
\hline $\mathrm{CO}_{2}$ & 0.009 & 0.066 & 0.009 & 0.066 & 0.001 \\
\hline $\mathbf{H}_{2}$ & 0.051 & 0.459 & 0.403 & - & 0.000 \\
\hline CO & 0.011 & 0.000 & 0.056 & - & 0.100 \\
\hline
\end{tabular}

728

729

730 


\section{References}

733 [1] J. Bierhals, Carbon Monoxide, in: Ullmann’s Encycl. Ind. Chem., Wiley-VCH Verlag GmbH \& Co. KGaA, Weinheim, Germany, 2001. doi:10.1002/14356007.a05_203.

[2] B. Cornils, W.A. Herrmann, Applied homogeneous catalysis with organometallic compounds, 1996.

[3] H. Bipp, H. Kieczka, Formamides, in: Ullmann’s Encycl. Ind. Chem., WileyVCH Verlag GmbH \& Co. KGaA, Weinheim, Germany, 2011. doi:10.1002/14356007.a12_001.pub2.

[4] M.A. Pacheco, C.L. Marshall, Review of dimethyl carbonate (DMC) manufacture and its characteristics as a fuel additive, Energy and Fuels. 11 (1997) 2-29. doi:10.1021/ef9600974.

[5] W. Reutemann, H. Kieczka, Formic Acid, in: Ullmann’s Encycl. Ind. Chem., Wiley-VCH Verlag GmbH \& Co. KGaA, Weinheim, Germany, 2000. doi:10.1002/14356007.a12_013.

[6] X. Yu, P.G. Pickup, Recent advances in direct formic acid fuel cells (DFAFC), J. Power Sources. 182 (2008) 124-132. doi:10.1016/j.jpowsour.2008.03.075.

[7] H. Cheung, R.S. Tanke, G.P. Torrence, Acetic Acid, in: Ullmann’s Encycl. Ind. Chem., Wiley-VCH Verlag GmbH \& Co. KGaA, Weinheim, Germany, 2000. doi:10.1002/14356007.a01_045.

[8] H. Held, A. Rengstl, D. Mayer, Acetic Anhydride and Mixed Fatty Acid Anhydrides, in: Ullmann’s Encycl. Ind. Chem., Wiley-VCH Verlag GmbH \& Co. KGaA, Weinheim, Germany, 2000. doi:10.1002/14356007.a01_065.

[9] T. Ohara, T. Sato, N. Shimizu, G. Prescher, H. Schwind, O. Weiberg, K. Marten, H. Greim, Acrylic Acid and Derivatives, in: Ullmann’s Encycl. Ind. Chem., 
Wiley-VCH Verlag GmbH \& Co. KGaA, Weinheim, Germany, 2003. doi:10.1002/14356007.a01_161.pub2.

[10] Ecoinvent Database 3.4, (2017). https://www.ecoinvent.org/ (accessed July 15, 2018).

[11] J.D. Medrano-García, R. Ruiz-Femenia, J.A. Caballero, Multi-objective optimization of combined synthesis gas reforming technologies, J. CO2 Util. 22 (2017) 355-373. doi:10.1016/j.jcou.2017.09.019.

[12] S. Lee, I.E. Grossmann, New algorithms for nonlinear generalized disjunctive programming, Comput. Chem. Eng. 24 (2000) 2125-2141. doi:10.1016/S00981354(00)00581-0.

[13] M. Ehrgott, M.M. Wiecek, Mutiobjective Programming, in: Mult. Criteria Decis. Anal. State Art Surv., Springer New York, New York, NY, 2005: pp. 667-708. doi:10.1007/0-387-23081-5_17.

[14] R. Pierantozzi, Carbon Monoxide, in: Kirk-Othmer Encycl. Chem. Technol., John Wiley \& Sons, Inc., Hoboken, NJ, USA, 2000. doi:10.1002/0471238961.0301180216090518.a02.

[15] K. Aasberg-Petersen, C.S. Nielsen, I. Dybkjær, J. Perregaard, Large scale methanol production from natural gas, Haldor Topsoe. (2008) 22.

[16] A.S.K. Raju, C.S. Park, J.M. Norbeck, Synthesis gas production using steam hydrogasification and steam reforming, Fuel Process. Technol. 90 (2009) 330336. doi:10.1016/j.fuproc.2008.09.011.

[17] R. Reimert, F. Marschner, H.-J. Renner, W. Boll, E. Supp, M. Brejc, W. Liebner, G. Schaub, Gas Production, 2. Processes, in: Ullmann’s Encycl. Ind. Chem., Wiley-VCH Verlag GmbH \& Co. KGaA, Weinheim, Germany, 2011. doi:10.1002/14356007.o12_o01. 
[18] Hydrogen and Carbon Monoxide: Synthesis Gases, in: Ind. Gases Process., Wiley-VCH Verlag GmbH \& Co. KGaA, Weinheim, Germany, n.d.: pp. 135184. doi:10.1002/9783527621248.ch5.

[19] M.A. Peña, J.P. Gómez, J.L.G. Fierro, New catalytic routes for syngas and hydrogen production, Appl. Catal. A Gen. 144 (1996) 7-57. doi:10.1016/0926860X(96)00108-1.

[20] E. Schwab, A. Milanov, S.A. Schunk, A. Behrens, N. Schödel, Dry reforming and reverse water gas shift: Alternatives for syngas production?, ChemieIngenieur-Technik. 87 (2015) 347-353. doi:10.1002/cite.201400111.

[21] X. Xiaoding, J.A. Moulijn, Mitigation of CO2by chemical conversion: Plausible chemical reactions and promising products, Energy and Fuels. 10 (1996) 305325. doi:10.1021/ef9501511.

[22] G.A. Olah, A. Goeppert, M. Czaun, G.K.S. Prakash, Bi-reforming of methane from any source with steam and carbon dioxide exclusively to metgas (CO-2H2) for methanol and hydrocarbon synthesis, J. Am. Chem. Soc. 135 (2013) 648-650. doi:10.1021/ja311796n.

[23] S. Afzal, D. Sengupta, A. Sarkar, M. El-Halwagi, and, N. Elbashir, Optimization Approach to the Reduction of CO 2 Emissions for Syngas Production Involving Dry Reforming, ACS Sustain. Chem. Eng. 6 (2018) 7532-7544. doi:10.1021/acssuschemeng.8b00235.

[24] C. Song, Tri-reforming: A new process concept for effective conversion and utilization of CO2 in flue gas from electric power plants, ACS Div. Fuel Chem. Prepr. 45 (2000) 772-776.

[25] M. Halmann, A. Steinfeld, Fuel saving, carbon dioxide emission avoidance, and syngas production by tri-reforming of flue gases from coal- and gas-fired power 
stations, and by the carbothermic reduction of iron oxide, Energy. 31 (2006) 3171-3185. doi:10.1016/j.energy.2006.03.009.

[26] Linde Engineering, Carbon monoxide, (2019). https://www.lindeengineering.com/en/process_plants/hydrogen_and_synthesis_gas_plants/gas_pro ducts/carbon_monoxide/index.html (accessed January 9, 2019).

[27] Pascal Marty; Arthur Darde; Antoine Hernandez;Jean-Marc Tsevery, Method for simultaneously producing hydrogen and carbon monoxide, 2010.

[28] F. Kasuya, T. Tsuji, High purity CO gas separation by pressure swing adsorption, Gas Sep. Purif. 5 (1991) 242-246. doi:10.1016/0950-4214(91)80031-Y.

[29] A.B. Hinchliffe, K.E. Porter, A comparison of membrane separation and distillation, Chem. Eng. Res. Des. 78 (2000) 255-268. doi:10.1205/026387600527121.

[30] N.N. Dutta, G.S. Patil, Developments in CO separation, Gas Sep. Purif. 9 (1995) 277-283. doi:10.1016/0950-4214(95)00011-Y.

[31] A.B. Hinchliffe, K.E. Porter, Gas Separation Using Membranes. 1. Optimization of the Separation Process Using New Cost Parameters, Ind. Eng. Chem. Res. 36 (1997) 821-829. doi:10.1021/ie9603272.

[32] Y.-I. Lim, J. Choi, H.-M. Moon, G.-H. Kim, Techno-economic comparison of absorption and adsorption processes for carbon monoxide (CO) separation from linze-donawitz gas (LDG), Korean Chem. Eng. Res. 54 (2016) 320-331. doi:10.9713/kcer.2016.54.3.320.

[33] GaBi Software and Database, (2017). http://www.gabi-software.com.

[34] Investing.com, (n.d.). https://www.investing.com/commodities/natural-gas (accessed February 15, 2018).

[35] A. Nuchitprasittichai, S. Cremaschi, Optimization of CO2 capture process with 
aqueous amines using response surface methodology, Comput. Chem. Eng. 35 (2011) 1521-1531. doi:10.1016/j.compchemeng.2011.03.016.

[36] B. Smith R J, M. Loganathan, M.S. Shantha, A Review of the Water Gas Shift Reaction Kinetics, Int. J. Chem. React. Eng. 8 (2010). doi:10.2202/15426580.2238.

[37] A. Wolf, A. Jess, C. Kern, Syngas Production via Reverse Water-Gas Shift Reaction over a Ni-Al2O3 Catalyst: Catalyst Stability, Reaction Kinetics, and Modeling, Chem. Eng. Technol. 39 (2016) 1040-1048. doi:10.1002/ceat.201500548.

[38] B. Lu, Y. Ju, K. Kawamoto, Conversion of producer gas using NiO/SBA-15 obtained with different synthesis methods, Int. J. Coal Sci. Technol. 1 (2014) 315-320. doi:10.1007/s40789-014-0037-y.

[39] Y. Wang, K.S. Chen, J. Mishler, S.C. Cho, X.C. Adroher, A review of polymer electrolyte membrane fuel cells: Technology, applications, and needs on fundamental research, Appl. Energy. 88 (2011) 981-1007. doi:10.1016/j.apenergy.2010.09.030.

[40] Hydrogenics, (n.d.). http://www.hydrogenics.com/hydrogen-productssolutions/fuel-cell-power-systems/stationary-stand-by-power/fuel-cell-megawattpower-generation-platform/ (accessed April 15, 2018).

[41] Y.C. Chiang, C.T. Chang, Single-objective and multiobjective designs for hydrogen networks with fuel cells, Ind. Eng. Chem. Res. 53 (2014) 6006-6020. doi:10.1021/ie404068p.

[42] S. Sircar, T.C. Golden, Separation Science and Technology Purification of Hydrogen by Pressure Swing Adsorption, (2006) 37-41. doi:10.1081/SS100100183. 
[43] K. Liu, C. Song, V. Subramani, Hydrogen and Syngas Production and Purification Technologies, 2009. doi:10.1002/9780470561256.

[44] R. Turton, R.C. Bailie, W.B. Whiting, J.A. Shaeiwitz, D. Bhattacharyya, Analysis, Synthesis and Design of Chemical Processes, Fourth, Prentice Hall, 2012.

[45] S.A. Papoulias, I.E. Grossmann, A structural optimization approach in process synthesis-II: Heat recovery networks, Comput. Chem. Eng. 7 (1983) 707-721. doi:10.1016/0098-1354(83)85023-6.

[46] R. Smith, Chemical Process Design and Integration, 1994. doi:10.1529/biophysj.107.124164.

[47] GAMS Development Corporation. General Algebraic System (GAMS) Release 25.0.3. Washington, DC, USA, 2018, (n.d.).

[48] R. Misener, C.A. Floudas, ANTIGONE: Algorithms for coNTinuous / Integer Global Optimization of Nonlinear Equations, J. Glob. Optim. 59 (2014) 503-526. doi:10.1007/s10898-014-0166-2.

[49] M. Appl, Ammonia, 2. Production Processes, in: Ullmann’s Encycl. Ind. Chem., Wiley-VCH Verlag GmbH \& Co. KGaA, Weinheim, Germany, 2011. doi:10.1002/14356007.o02_011.

[50] A. de Klerk, Fischer-Tropsch Process, in: Kirk-Othmer Encycl. Chem. Technol., John Wiley \& Sons, Inc., Hoboken, NJ, USA, 2013. doi:10.1002/0471238961.fiscdekl.a01.

[51] A.C. Vosloo, Fischer-Tropsch: A futuristic view, Fuel Process. Technol. 71 (2001) 149-155. doi:10.1016/S0378-3820(01)00143-6.

[52] M.J. Kirschner, A. Alekseev, S. Dowy, M. Grahl, L. Jansson, P. Keil, G. Lauermann, M. Meilinger, W. Schmehl, H. Weckler, C. Windmeier, Oxygen, in: 

doi:10.1002/14356007.a18_329.pub2.

884 [53] Eurostat Database, Electricity prices by type of user, (2017).

885 https://ec.europa.eu/eurostat/tgm/refreshTableAction.do;jsessionid=W_AzykoJwl eWzqhBFk5K4y1LOZivbHBmC4qehHPdshmkD_r5wW0!1742705336?tab=table\&plugin=1\&pcode=ten00117\&language=en .

888 